\title{
Companies under stress: the impact of shocks on the production network
}

\author{
Róbert Pálovics ${ }^{1 *}$ (D) Primož Dolenc ${ }^{2}$ and Jure Leskovec ${ }^{1}$
}

\author{
"Correspondence: \\ palovics@stanford.edu \\ 'Department of Computer Science, \\ Stanford University, 353 Jane \\ Stanford Way, Stanford, CA 94305 , \\ USA \\ Full list of author information is \\ available at the end of the article
}

\begin{abstract}
In this paper we analyze the effect of shocks in production networks. Our work is based on a rich dataset that contains information about companies from Slovenia right after the financial crisis of 2008. The processed data spans for 8 years and covers the transaction history as well as performance indicators and various metadata of the companies. We define sales shocks at different levels, and identify companies impacted by them. Next we investigate stress, the potential immediate upstream and downstream impact of a shock within the production network. We base our main findings on a matched pairs analysis of stressed companies. We find that both shock and stress are associated with reporting bankruptcy in the future and that stress foremost impacts the future sales of customers. Furthermore, we find evidence that stress not only results in performance losses but the reconfiguration of the production network as well. We show that stressed companies actively seek for new trading partners, and that these new links often share the industry of the shocked company. These results suggest that both stressed customers and suppliers react quickly to stress and adjust their trading relationships.
\end{abstract}

Keywords: Financial contagion; Shock propagation; Network evolution

\section{Introduction}

Multimodal temporal links between companies result in the complex structure of today's economy. Companies rely on the input and output of their trading partners. These linkages between suppliers and customers form the production network. The network consists of nodes (companies) with directed edges that define supplier and customer relations. This network is characterized by temporal dynamics since companies may change their suppliers and customers especially during turbulent times like the period after the 2008 global crisis. ${ }^{1}$ Due to unforeseen events companies experience shocks, and may be unable to fulfill their liabilities to others, and therefore impose stress on their upstream supplier and downstream customer partners. The effect of these individual company-level shocks [1,2] in the ever-changing production network is still not completely understood.

Previous works cover results on economic networks of financial entities [3-14] and report characteristics of complex networks known in other domains, such as their power-

\footnotetext{
${ }^{1}$ https://en.wikipedia.org/wiki/Financial_crisis_of_2007-2008
}

(0) The Author(s) 2021. This article is licensed under a Creative Commons Attribution 4.0 International License, which permits use sharing, adaptation, distribution and reproduction in any medium or format, as long as you give appropriate credit to the original author(s) and the source, provide a link to the Creative Commons licence, and indicate if changes were made. The images or other third party material in this article are included in the article's Creative Commons licence, unless indicated otherwise in a credit line to the material. If material is not included in the article's Creative Commons licence and your intended use is not permitted by statutory regulation or exceeds the permitted use, you will need to obtain permission directly from the copyright holder. To view a copy of this licence, visit http://creativecommons.org/licenses/by/4.0/. 
law degree distribution [6] or the bow-tie structure $[6,15]$. Although multiple theoretical models were proposed for financial contagion due to connectedness [16], yet there is limited empirical validation $[3,11,12,16]$ and the underlying network is often roughly estimated without empirical data on the links [3]. Promising theoretical models of production networks has been recently proposed $[17,18]$. In contrast, there are only a few, mainly cross-sectional empirical studies addressing specifically company level supplier-customer relations and describing production networks [19-21]. These studies suggest that the network topology and the firms' immediate connections have a crucial role in shock propagation. Fujiwara and Aoyama [19] provide a very detailed snapshot of a Japanese production network from 2006. In their analysis, the authors raise attention to the so-called "chain of bankruptcy", meaning that when a firm goes into financial insolvency, its relations have elevated risk of going into bankruptcy. [20] examines the idiosyncratic risk in the context of firm interactions and highlight the tendency of companies to interact with firms with similar risk. According to Korniyenko et al. [21] the presence of "central players" in a specific product's market represents significant risk for potential supply shocks since its crisis can destabilize a whole cluster of the production system.

As reviewed by [22], only a few studies focus on the propagation of the idiosyncratic shocks at the individual company level. A key assumption of these analyses is that suppliers impose significant output losses on their customers. Barrot et al. [2] show that natural disasters strongly influence not only the companies nearby within the region, but their customers as well, which consistently report sales growth drops. Studies that empirically investigate the immediate effects of shocks [2, 22-24] suggest sales growth as a main indicator of company performance.

Our work contributes to this stream of literature in several ways. We take advantage of a longitudinal dataset that makes it possible to analyzing the dynamics of the production network, especially during the times of the financial crises. In contrast to the earlier literature [2], we shift the focus from supply shocks, or sector level shocks [18, 22] to empirically investigate the consequences of drops in the sales of individual companies. Our work is based on a dataset covering the economic activities within Slovenia between 2008 and 2015, hence right after the global crisis of 2008 during the economic recession. The data includes timestamped transactions between the companies that we aggregate within each year. These yearly network snapshots reflect the changing customer-supplier relationships of companies. Furthermore, the data contains information on the industry sectors and the net sales of companies on a yearly basis. Our dataset is unique and different from other previously reported data $[2,19-21,23,24]$ since:

- The dataset is not limited to a single bank since all the information is available from the central bank of the country.

- The data contains all transactions within the country that have been sent through the Trans-European Automated Real-time Gross settlement Express Transfer system ${ }^{2}$ (TARGET2), which is the large-value international payments and settlement system for the Eurosystem, the eurozone's system of central banks.

- The yearly balance sheet data indicates the performance of each company.

- The data is longitudinal and completely covers the 8 years between 2008 and 2015.

${ }^{2}$ https://en.wikipedia.org/wiki/TARGET2 


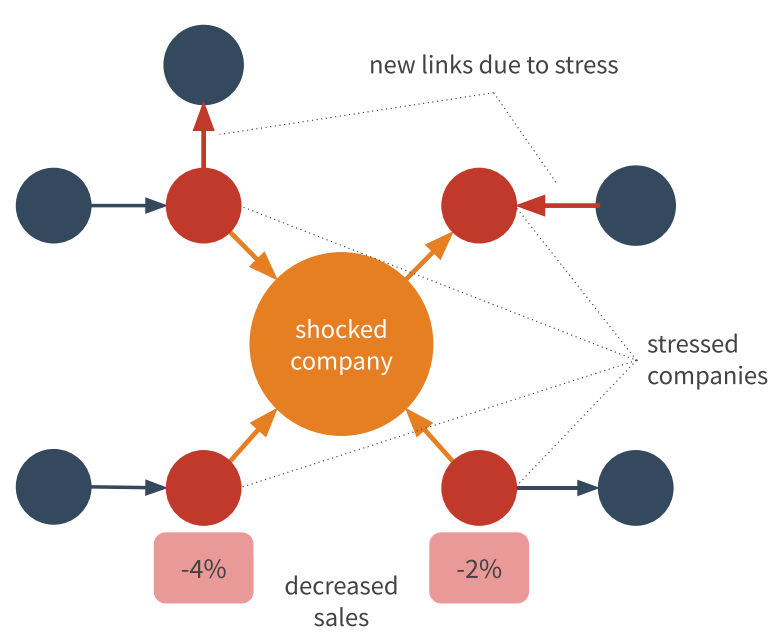

Figure 1 Results of a shock within the production network. Performance of customers in the neighborhood may drop within a year after the shock. In general, both customers and suppliers immediately respond and seek for new trading partners

Relying on this information we aim to understand how shocked companies affect the behavior of their partners within the production network. We define shocks based on yearly sales changes available from the balance sheets and consider a company shocked if it experiences a sudden drop in its sales. We define the adjacent, immediate upstream, downstream and bi-directional partners of shocked companies stressed and analyze their behavior in the upcoming years.

More specifically, as illustrated in Fig. 1, we intend to examine the impact of shocked companies on the survival of their trading partners. We hypothesize that stressed companies experience a loss in performance during the years following the shocking event, and that stress may even contribute to their future bankruptcy. Furthermore, we assume that stress drives the reconfiguration of relations in the long run. Specifically, stressed companies react to the shocking event according to their relations with the shocked company: customers initiate new relationships with new suppliers, and suppliers initiate new links with customers accordingly.

In order to address these questions, we employ a matched pairs quasi-experimental design and match each stressed company to a company that does not experience shock or stress and has similar industrial, sales performance and network characteristics as the stressed one. We compare the future aspects of the stressed and control groups, and seek to answer if stress influences future economical performance or induces any changes within the production network.

Our results suggest that both shock and stress is associated with a higher chance of bankruptcy, and stress results in future decrease of sales performance. Furthermore, we find that stressed companies quickly adjust their relationships and seek for new trading connections suggesting that this behavior is key for resiliency against idiosyncratic shock propagation. The fact that new links often appear from the same industry as the shocked node indicate that these replace the previously shocked partner.

The rest of the paper is organized as follows. We provide a detailed description of the dataset in Sect. 2. Next in Sect. 3 we describe in detail the matched pairs design and 
Figure 2 Structure of the processed dataset. We define customer-supplier relations on a yearly basis based on transaction history. Industrial sector and yearly sales information is also available for the companies
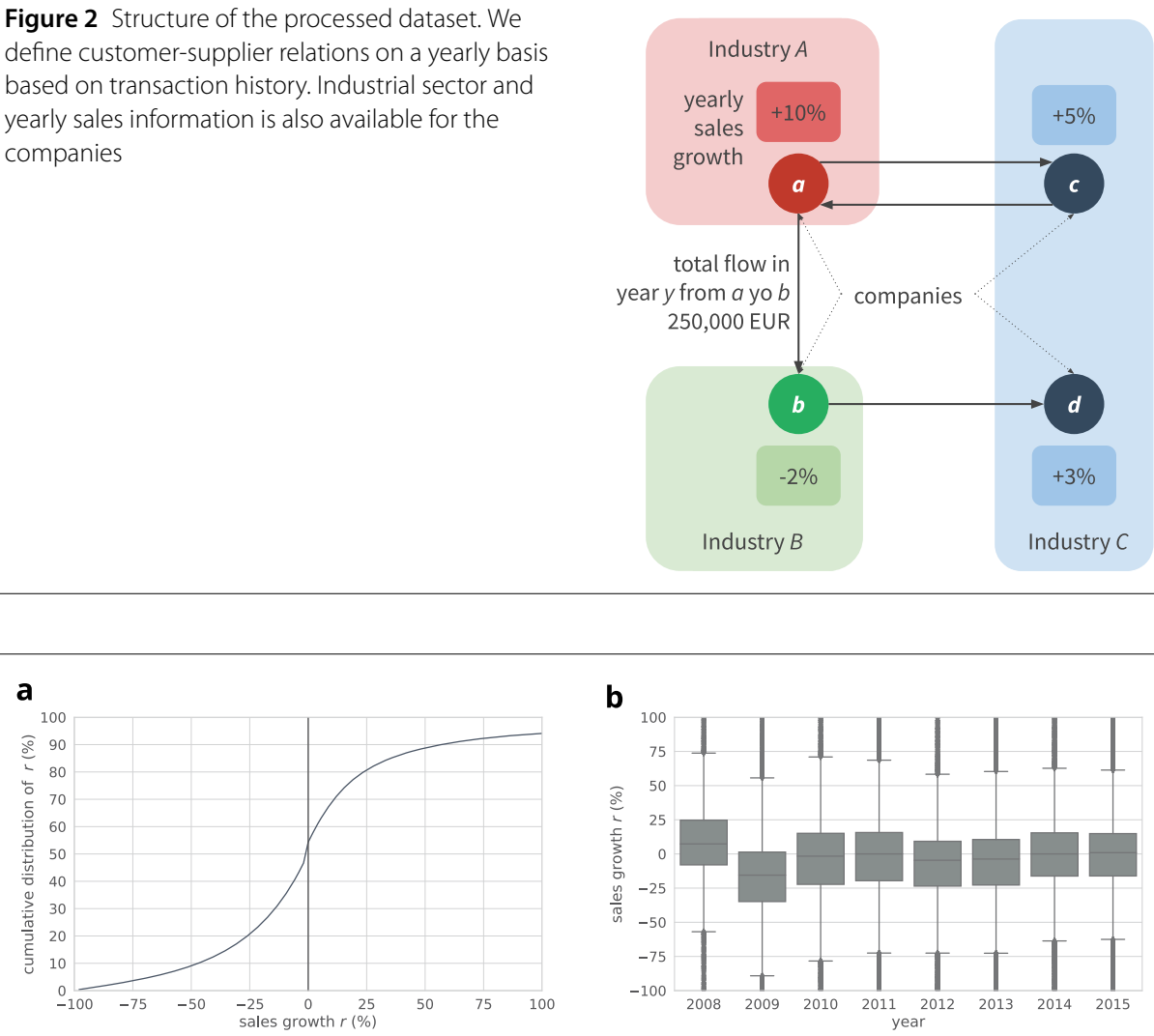

Figure 3 (a) Cumulative distribution of the yearly sales growth. (b) Yearly distributions of sales growth shown as box plots

the corresponding analyses. We present our results then in Sect. 4 and conclude them in Sect. 5.

\section{Dataset}

Our work is based on a data of the economic activity of Slovenia (see Fig. 2). Briefly, the data covers yearly balance sheet information, daily transaction records and additional metadata of companies within the country. The yearly balance sheet information is available between 2000 and 2015. Following the concepts of [2, 23, 24], here we investigate sales growth, i.e., the yearly relative sales changes of companies. Note that we exclude from our analysis changes larger than $100 \%$, which cover $6 \%$ of all the available records (see Fig. 3a). The median value of sales changes vary across the years (see Fig. 3b), showing a large drop in 2009. The data includes hierarchical industry sectors, defined by the national SKD system. ${ }^{3}$ We use the second level of this ontology, and since our analysis focuses on the production network, we remove companies related to financial services, or governmental activities resulting in 78 distinct sectors within the dataset (see Table 1). The metadata also indicates if a company went bankrupt anytime until 2015. In addition, we have access to all transactions recorded in the Trans-European Automated Real-time Gross settlement Express Transfer system (TARGET2) between 2008 and 2018. Compa- 
Table 1 Industry categories sorted by their frequency within the data

\begin{tabular}{|c|c|}
\hline$\%$ of companies & Name \\
\hline 18.12 & Wholesale trade, except of motor vehicles and motorcycles \\
\hline 6.94 & Architectural and engineering activities, technical testing and analysis \\
\hline 6.13 & Specialised construction activities \\
\hline 5.57 & Activities of head offices, management consultancy activities \\
\hline 5.19 & Construction of buildings \\
\hline 4.91 & Real estate activities \\
\hline 4.35 & Manufacture of fabricated metal products, except machinery and equipment \\
\hline 3.98 & Retail trade, except of motor vehicles and motorcycles \\
\hline 3.26 & Land transport and transport via pipelines \\
\hline 3.14 & Wholesale and retail trade and repair of motor vehicles and motorcycles \\
\hline 2.9 & Computer programming, consultancy and related activities \\
\hline 2.2 & Legal and accounting activities \\
\hline 1.81 & Manufacture of machinery and equipment n.e.c. \\
\hline 1.61 & Electricity, gas, steam and air conditioning supply \\
\hline 1.52 & Food and beverage service activities \\
\hline 1.47 & Civil engineering \\
\hline 1.37 & Manufacture of rubber and plastic products \\
\hline 1.31 & Warehousing and support activities for transportation \\
\hline 1.23 & Scientific research and development \\
\hline 1.22 & Advertising and market research \\
\hline 1.15 & $\begin{array}{l}\text { Manufacture of wood and products of wood and cork, except furniture, } \\
\text { manufacture of articles of straw and plaiting mat. }\end{array}$ \\
\hline 1.06 & Accommodation \\
\hline 0.97 & Manufacture of furniture \\
\hline 0.89 & Manufacture of food products \\
\hline 0.89 & Repair and installation of machinery and equipment \\
\hline 0.87 & Printing and reproduction of recorded media \\
\hline 0.81 & Manufacture of other non-metallic mineral products \\
\hline 0.78 & Manufacture of electrical equipment \\
\hline 0.71 & Other professional, scientific and technical activities \\
\hline 0.7 & Waste collection, treatment and disposal activities, materials recovery \\
\hline 0.7 & Manufacture of computer, electronic and optical products \\
\hline 0.69 & Travel agency, tour operator and other reservation service and related activities \\
\hline 0.64 & Telecommunications \\
\hline 0.59 & Publishing activities \\
\hline 0.58 & Human health activities \\
\hline 0.57 & Employment activities \\
\hline 0.49 & Services to buildings and landscape activities \\
\hline 0.48 & Manufacture of motor vehicles, trailers and semi-trailers \\
\hline 0.48 & Office administrative, office support and other business support activities \\
\hline 0.45 & Manufacture of chemicals and chemical products \\
\hline 0.45 & Rental and leasing activities \\
\hline 0.43 & $\begin{array}{l}\text { Motion picture, video and television programme production, sound recording } \\
\text { and music publishing activities }\end{array}$ \\
\hline 0.43 & Crop and animal production, hunting and related service activities \\
\hline 0.41 & Sports activities and amusement and recreation activities \\
\hline 0.38 & Manufacture of textiles \\
\hline 0.38 & Other personal service activities \\
\hline 0.38 & Other manufacturing \\
\hline 0.37 & Manufacture of basic metals \\
\hline 0.34 & Manufacture of paper and paper products \\
\hline 0.31 & Water collection, treatment and supply \\
\hline 0.3 & Information service activities \\
\hline 0.28 & Security and investigation activities \\
\hline 0.28 & Programming and broadcasting activities \\
\hline 0.27 & Manufacture of wearing apparel \\
\hline 0.25 & Other mining and quarrying \\
\hline 0.23 & Forestry and logging \\
\hline 0.21 & Gambling and betting activities \\
\hline 0.18 & Manufacture of other transport equipment \\
\hline 0.17 & Repair of computers and personal and household goods \\
\hline
\end{tabular}


Table 1 (Continued)

\begin{tabular}{ll}
\hline \% of companies & Name \\
\hline 0.17 & Creative, arts and entertainment activities \\
0.13 & Manufacture of beverages \\
0.11 & Postal and courier activities \\
0.09 & Air transport \\
0.08 & Residential care activities \\
0.08 & Remediation activities and other waste management services \\
0.08 & Water transport \\
0.08 & Manufacture of leather and related products \\
0.08 & Activities of membership organisations \\
0.06 & Veterinary activities \\
0.06 & Libraries, archives, museums and other cultural activities \\
0.05 & Fishing and aquaculture \\
0.05 & Sewerage \\
0.04 & Manufacture of basic pharmaceutical products and pharmaceutical preparations \\
0.03 & Social work activities without accommodation \\
0.02 & Manufacture of coke and refined petroleum products \\
0.01 & Mining support service activities \\
0.01 & Extraction of crude petroleum and natural gas \\
0.01 & Mining of coal and lignite \\
\hline &
\end{tabular}

Table 2 Properties of the processed dataset

\begin{tabular}{lc}
\hline time span & $2008-2015$ \\
number of companies & 24,861 \\
number of industry sectors & 78 \\
total number of transactions & 478,620 \\
\hline
\end{tabular}
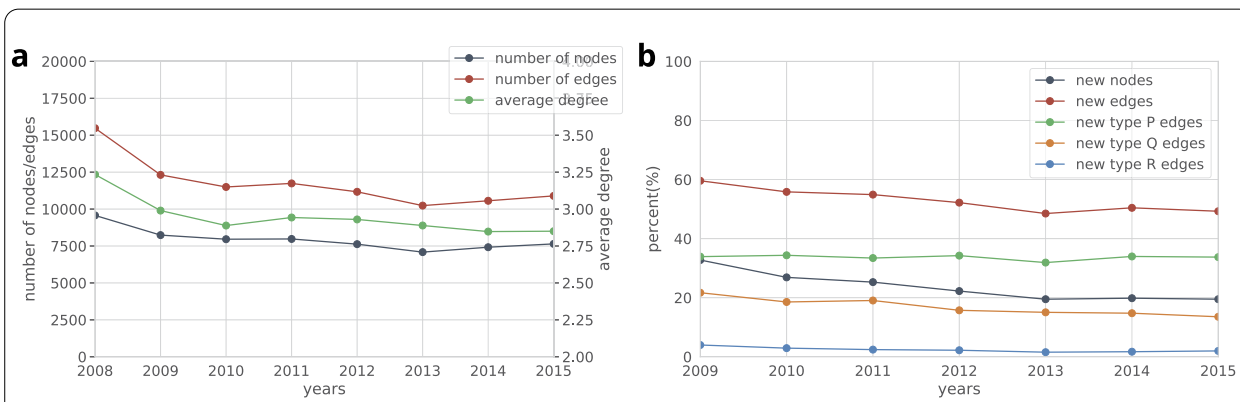

Figure 4 (a) Yearly graph statistics. The average degree, indicated in the right axis, is roughly constant while the overall activity decreases in the network. (b) Yearly fraction new edges and nodes in the production network. We distinguish between three new edge types, type $P$ connects two already observed companies, type $\mathrm{Q}$ connects a newly observed company to an already seen one, type R connects two companies that have never been observed before

nies of the study are required to send funds over 50k EUR via TARGET2, hence the data covers all of their large transactions. Since the balance sheet information is available on a yearly basis, we aggregate the transactions and define yearly directed networks of companies where for year $y$ a directed edge $(A, B)$ exists between companies $A$ and $B$, if $A$ sent at least one transaction to $B$ in $y$. We use the yearly aggregated networks to approximate customer-supplier relations.

Throughout our analyses we consider the period between 2008 and 2015 where all the listed information is available. Table 2 summarizes the properties of the processed dataset. In order to describe the production network, in Fig. 4a we plot yearly graph statistics. Note 

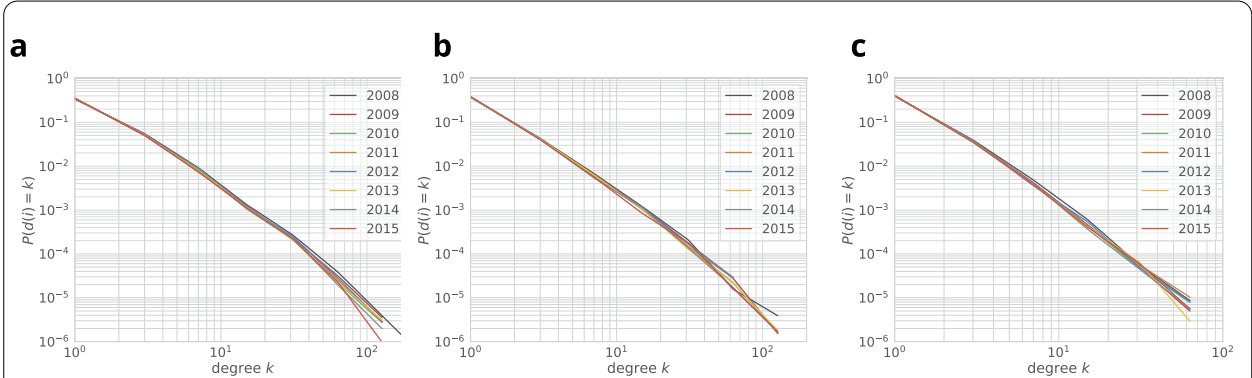

Figure 5 total degree (a), in-degree (b) and out-degree (c) distributions computed from yearly graph snapshots. While the underlying network changes, the power-law degree distribution is stable with exponent 2.27

that the yearly number of edges declines, while the average degree only slightly decreases. In Fig. 4b we show for each year $y$ the percent of nodes and edges that are first observed in year $y$. We distinguish three edge categories: a new edge can connect two already observed companies $(\mathrm{P})$, it can connect a newly observed company to an already seen one $(\mathrm{Q})$, and it can connect two companies that we never observed before (R). While several new edges appear each year, the fraction of $R$ edges is low, i.e., most of the new edges connect to an already existing part of the network. In Fig. 5 we plot the degree distributions of the yearly networks. Despite the varying number of nodes and edges, the overall degree distribution does not change over the years. Note that the transitivity of these graphs are always below 0.005 , indicating the lack of triangles. This property is specific to production networks, and it has been reported previously [19].

\section{Methods}

We follow previous related studies that use sales growth as a primary outcome variable $[2,23,24]$. We implement a time sensitive matched pairs based computational analysis in order to understand the effects of stress (see Fig. 6). Earlier studies report results on correlation based linear models [2, 23]. In contrast, our approach does not imply linear relationships. Furthermore, the variables of interest of this study are difficult to estimate overall, which can result in poorly fitted regression models.

\subsection{Definition of shock and stress}

First, we define yearly sales growth of a company as

$$
r(c, y)=\frac{s(c, y)-s(c, y-1)}{s(c, y-1)}
$$

where $s(c, y)$ indicates the sales of company $c$ in year $y$. Since company sales are nonnegative, and we restrict our analysis for changes less than $100 \%,-1 \leq r(c, y) \leq 1$. Based on this indicator we consider a company $c$ in year $y$ shocked if

$$
r(c, y-1)>0, \quad r(c, y)<-v
$$

where shock level $v$ is a predefined parameter. In other words, we define a company shocked in a year if it suffers a great sales loss but operated without any decrease in sales 


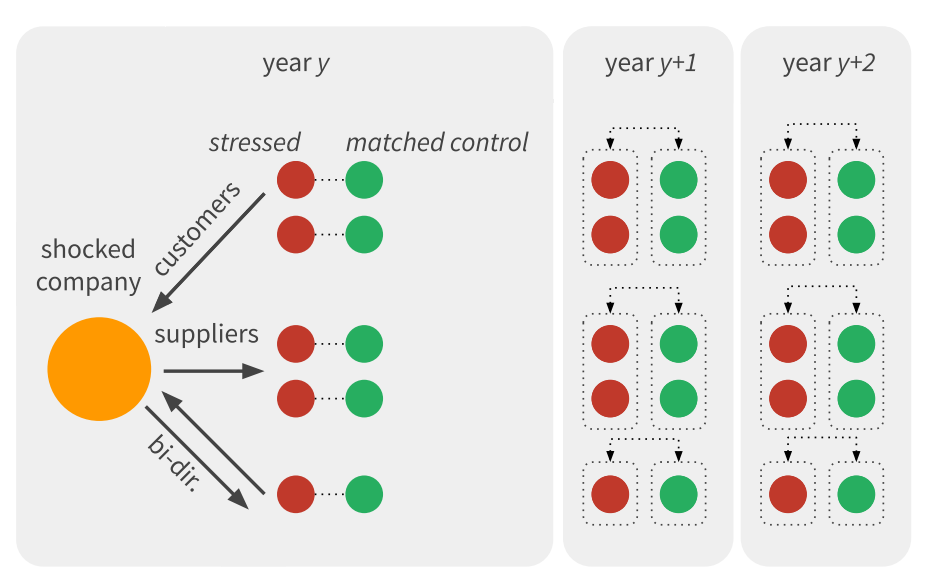

Figure 6 Concept of matched pairs analysis. We define partners of shocked companies stressed and match them to similar control companies. We compare the two groups during the two years following the original shock event

in the previous year and hence showed no sign of suffering a shock. Note that once a company is shocked in year $s$, we exclude it from the analysis of the following years $y>s$.

We analyze the potential effect of these shocked companies on their network neighborhoods and define stressed companies (see Fig. 6). We consider company $t$ stressed at level $v$ in year $y$ if

- it has transaction record(s) from years earlier than $y$ that links it to a company shocked at level $v$ in year $y$,

- initially does not indicate decreasing performance in year $y, r(t, y)>0$.

Since transactions reflect customer-supplier relations, we distinguish between stressed nodes depending on their relation to the shocked node. The successors of the shocked node are defined as suppliers, and the predecessors of the node are customers. We also distinguish bidirectional relations where cash flow was observed in both ways between the shocked and stressed companies. This categorization results in stressed suppliers, stressed customers and stressed bidirectional partners.

\subsection{Matching procedure}

For each of the identified stressed company $t$ we randomly select a matched control $c$ company that

- has the same industry classification as the stressed one,

- has sales $s(c, y)$ in year that is similar to $s(t, y)$, and may differ up to $10 \%$, i.e., $|s(t, y)-s(c, y)| / s(t, y)<0.1$,

- does not indicate decreasing performance in year $y, r(c, y)>0$,

- has never been shocked until year $y$,

- has similar in- and out-degree in year $y$ to $t$.

For degree matching we match nodes with in/out-degrees that are at the same magnitude. This is particularly important since we have shown in Fig. 5 that both the in- and outdegree distributions are heavy tailed. 


\subsection{Statistical analyses}

First we investigate if shock events are related to bankruptcies and calculate the fraction of companies that eventually become bankrupt amongst all shocked and non-shocked companies. We repeat the analysis at shock levels between $20 \%$ and $80 \%$ and report the results of chi-square statistics. Next we compare stressed nodes to their matched control group. We calculate the fraction of bankrupt companies within the two groups at shock levels between $20 \%$ and $80 \%$ and report the results of chi-square statistics.

In order to put the bankruptcy related results into a wider context and estimate the effect sizes of the proposed shocked and stressed statuses, as a secondary analysis, we perform a logistic regression based classification on bankruptcy. We include all companies and aim to predict future bankruptcy based on company performance (sales and sales growth), the industry classification, the number of immediate relationships (suppliers and customers) and the status of the company (if the company ever suffered from stress, and shock). We are following a stepwise approach and in total, we run three models. The baseline model (STEP1) includes the industry classification, the mean total sales, the relative sales growth, the mean number of yearly customers (log transformed) and the mean number of yearly supplies (log transformed). In STEP2 we added the shock status (Yes/No, at 50\% level) into the model in addition to the baseline predictors. Finally, (STEP3) the model includes stress (Yes/No,at 50\% level) along with all the previous predictors. The continuous predictors are centered around the mean. We provide the statistical significance and parameter estimates of the individual predictors for the best model.

In order to assess how stress affects future sales performance, we compare the sales performance of the stressed companies to their control groups in the two years following the original shock event $(y+1, y+2)$. We conduct our analysis at shock levels between $20 \%$ and $80 \%$. We perform independent $t$-tests between the stressed and control groups. In order to examine potential association between stress and the frequency of shocks, we perform chi-square tests.

We investigate network dynamics around the stressed and control nodes. We compare the number of new customers, suppliers and bidirectional relations that the stressed and control groups establish in one and two years following the original shock event. As presented in Sect. 2, the yearly customer-supplier networks have heavy tailed degree distributions. Hence we test the significance of these results with the non-parametric Kolmogorov-Smirnov test.

Finally, we ask if stressed companies potentially "replace" their shocked partners and find new connections within the industry sector of the shocked node. We investigate at $50 \%$ shock level the new suppliers of shocked customers and the new customers of shocked suppliers. We calculate the ratio of stressed nodes where the shocked neighbor(s) industry categories can be found within the new links initiated in followup years $(y+1$ and $y+2)$.

\section{Results}

Overall, the economical crisis results in several shocked and stressed nodes, e.g., at 50\% shock level there are roughly 500 shocked as well as stressed companies within each year following 2008 (see Fig. 7, Tables 3, 4). Our results show that companies are being shocked most prominently in 2009, which is consistent with the results of Fig. 3b, where 2009 appears to be the worst year in terms of sales indicating the burden of the 2008 financial crisis. 


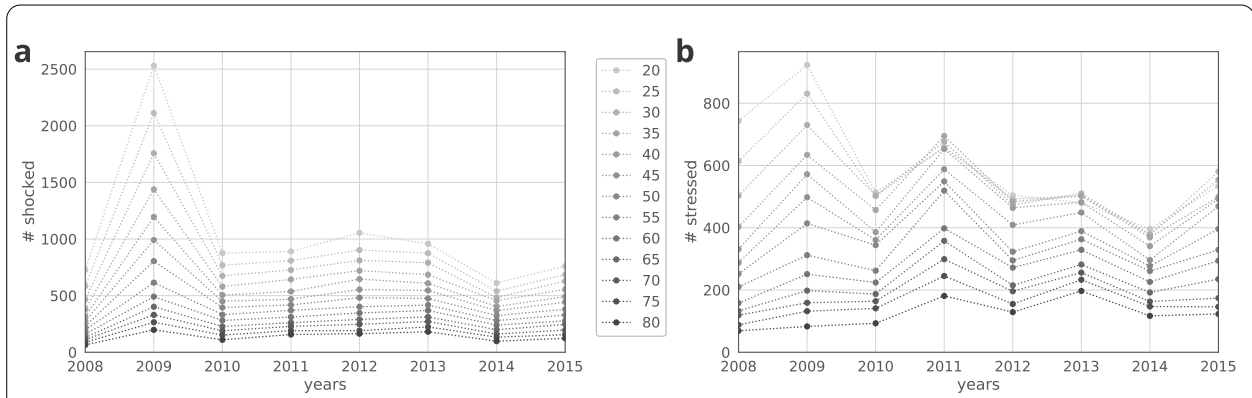

Figure 7 (a) Number of shocked companies per year at different shock levels. (b) Number of stressed companies per year at different shock levels

Table 3 Number of shocked companies per year at different shock levels

\begin{tabular}{|c|c|c|c|c|c|c|c|c|c|c|c|c|c|}
\hline \multirow[t]{2}{*}{ Year } & \multicolumn{13}{|c|}{ Shock level } \\
\hline & 20 & 25 & 30 & 35 & 40 & 45 & 50 & 55 & 60 & 65 & 70 & 75 & 80 \\
\hline 2008 & 728 & 585 & 466 & 380 & 316 & 276 & 231 & 197 & 161 & 130 & 111 & 88 & 65 \\
\hline 2009 & 2531 & 2112 & 1757 & 1438 & 1195 & 991 & 805 & 615 & 491 & 402 & 330 & 265 & 198 \\
\hline 2010 & 875 & 768 & 675 & 580 & 505 & 450 & 395 & 332 & 281 & 228 & 190 & 152 & 110 \\
\hline 2011 & 890 & 809 & 727 & 643 & 537 & 469 & 418 & 370 & 311 & 261 & 229 & 190 & 157 \\
\hline 2012 & 1054 & 903 & 811 & 721 & 646 & 554 & 482 & 402 & 347 & 290 & 247 & 191 & 164 \\
\hline 2013 & 958 & 875 & 791 & 685 & 609 & 546 & 475 & 417 & 369 & 312 & 272 & 224 & 181 \\
\hline 2014 & 612 & 539 & 483 & 455 & 404 & 367 & 324 & 280 & 240 & 199 & 161 & 133 & 98 \\
\hline 2015 & 760 & 686 & 629 & 555 & 491 & 443 & 380 & 329 & 278 & 246 & 196 & 155 & 123 \\
\hline
\end{tabular}

Table 4 Number of stressed companies per year at different shock levels

\begin{tabular}{|c|c|c|c|c|c|c|c|c|c|c|c|c|c|}
\hline \multirow[t]{2}{*}{ Year } & \multicolumn{13}{|c|}{ Stress level } \\
\hline & $\overline{20}$ & 25 & 30 & 35 & 40 & 45 & 50 & 55 & 60 & 65 & 70 & 75 & 80 \\
\hline 2008 & 743 & 614 & 503 & 403 & 331 & 288 & 252 & 210 & 158 & 133 & 119 & 88 & 69 \\
\hline 2009 & 923 & 831 & 730 & 634 & 572 & 498 & 414 & 312 & 251 & 198 & 159 & 132 & 83 \\
\hline 2010 & 514 & 502 & 503 & 457 & 386 & 361 & 344 & 262 & 224 & 187 & 164 & 141 & 93 \\
\hline 2011 & 657 & 659 & 677 & 695 & 653 & 588 & 549 & 519 & 398 & 358 & 299 & 245 & 181 \\
\hline 2012 & 504 & 492 & 474 & 484 & 464 & 409 & 323 & 295 & 272 & 215 & 196 & 155 & 129 \\
\hline 2013 & 480 & 503 & 510 & 502 & 482 & 449 & 389 & 363 & 329 & 282 & 256 & 233 & 197 \\
\hline 2014 & 396 & 378 & 379 & 369 & 341 & 296 & 277 & 261 & 226 & 192 & 163 & 147 & 117 \\
\hline 2015 & 534 & 581 & 554 & 499 & 492 & 469 & 396 & 329 & 294 & 235 & 174 & 146 & 123 \\
\hline
\end{tabular}

\subsection{Shock, stress and bankruptcies}

We address the question if shock events are related to bankruptcies. Figure 8 shows the fraction of companies that eventually become bankrupt within shocked and non-shocked companies. The results of the chi-square statistic shows that shocks and bankruptcy are significantly associated at all shock levels (all $p<0.001$ ). These translate to odds ratios (OR) around 2 (see Fig. 8b, e.g., at shock level $50 \% \mathrm{OR}=1.95, p<0.001$ ). Hence for every company with at least $50 \%$ drop in performance, almost twice as many will be bankrupted in the following years as will without being shocked.

More importantly, stress is also significantly related to bankruptcy (see Fig. 9). The fraction of bankrupt companies differ by groups, stressed companies are more likely to be bankrupt then their matched controls (see Fig. 9a). The relationship is significant at all shock levels, and translates to odds ratios (OR) around 1.5 (see Fig. 9b). E.g., at shock level $50 \% \mathrm{OR}=1.57, p<0.001$, meaning that the likelihood to be bankrupt is 1.5 times higher for a stressed node (defined by a $50 \%$ cutoff) than for a control node. 

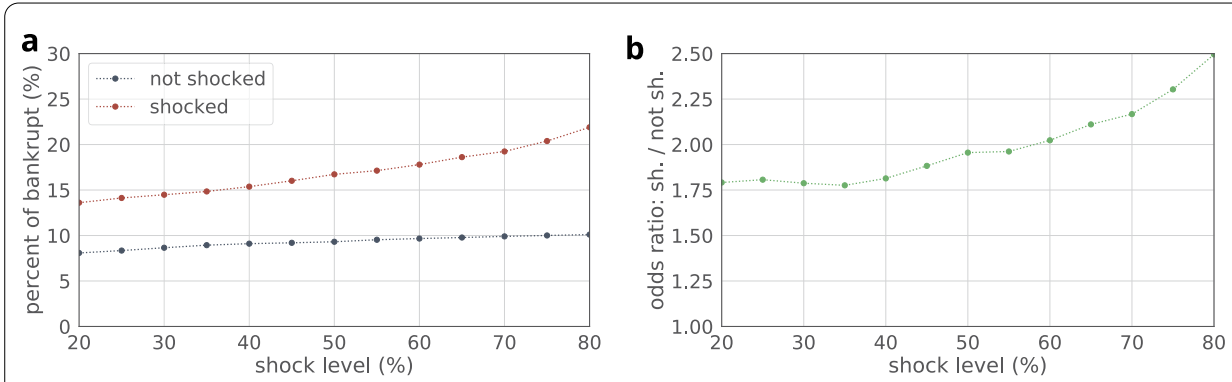

Figure 8 (a) Fraction of bankrupt companies among shocked and non-shocked ones. (b) Odds-ratio of bankruptcy. We run chi-square test per shock level and find all results significant with $p<0.001$
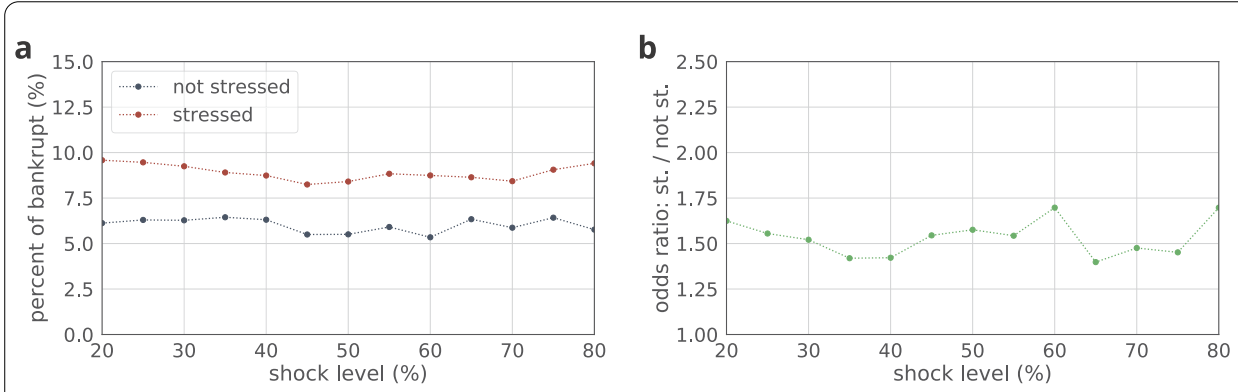

Figure 9 (a) Fraction of bankrupt companies among stressed and non-stressed ones. (b) Odds-ratio of bankruptcy. We run chi-square test per shock level and find all results significant with $p<0.001$

Table 5 Summary of the logistic regression analysis. Variables included in the final model of bankruptcy (pseudo- $R^{2}=0.06$ ). Parameter estimates $\beta$ with 95\% confidence intervals $(\mathrm{Cl})$ are provided. In the table we report industry categories with significant impact in the model. $* p<0.05$, $* * p<0.01, * * * p<0.001$

\begin{tabular}{lclclcr}
\hline & $\beta$ & std & \multicolumn{1}{l}{ z } & $p$ & Cl: [0.025 & $0.975]$ \\
\hline Intercept & -2.872 & 0.466 & -6.16 & $<0.001 * * *$ & -3.786 & -1.958 \\
stress & 0.428 & 0.058 & 7.332 & $<0.001 * * *$ & 0.313 & 0.542 \\
shock & 0.737 & 0.058 & 12.616 & $<0.001 * * *$ & 0.622 & 0.851 \\
customers & 0.173 & 0.027 & 6.503 & $<0.001 * * *$ & 0.121 & 0.226 \\
sales & -0.275 & 0.08 & -3.445 & $0.001 * * *$ & -0.431 & -0.118 \\
Construction of buildings & 1.405 & 0.472 & 2.976 & $0.003 * *$ & 0.48 & 2.33 \\
Legal and accounting activities & -2.177 & 0.744 & -2.927 & $0.003 * *$ & -3.634 & -0.719 \\
Printing and reproduction of recorded media & 1.171 & 0.512 & 2.286 & $0.022 *$ & 0.167 & 2.176 \\
Gambling and betting activities & 1.389 & 0.62 & 2.241 & $0.025 *$ & 0.174 & 2.604 \\
Manufacture of wearing apparel & 1.276 & 0.598 & 2.134 & $0.033 *$ & 0.104 & 2.45 \\
Employment activities & 1.0952 & 0.539 & 2.032 & $0.042 *$ & 0.039 & 2.152 \\
Manufacture of paper and paper products & 1.172 & 0.583 & 2.01 & $0.044 *$ & 0.029 & 2.315 \\
Food and beverage service activities & 0.980 & 0.497 & 1.974 & $0.048 *$ & 0.007 & 1.954 \\
\hline
\end{tabular}

We continue the analysis of bankruptcies with an additional logistic regression based analysis. The pseudo- $R^{2}$ value of the baseline is fairly low (0.044) indicating that the task is hard in general. However, including shock improves the pseudo- $R^{2}$ score $\left(R^{2}=0.055\right)$, which is also increased by adding the stress $\left(R^{2}=0.060\right)$ into the model (STEP3). We provide the statistical significance of the predictors for the final, best performing model (STEP3) in Table 5. According to the results both the stress $(\beta=0.428, p<0.001)$ and shock $(\beta=0.737, p<0.001)$ status of the company is significantly associated with fu- 


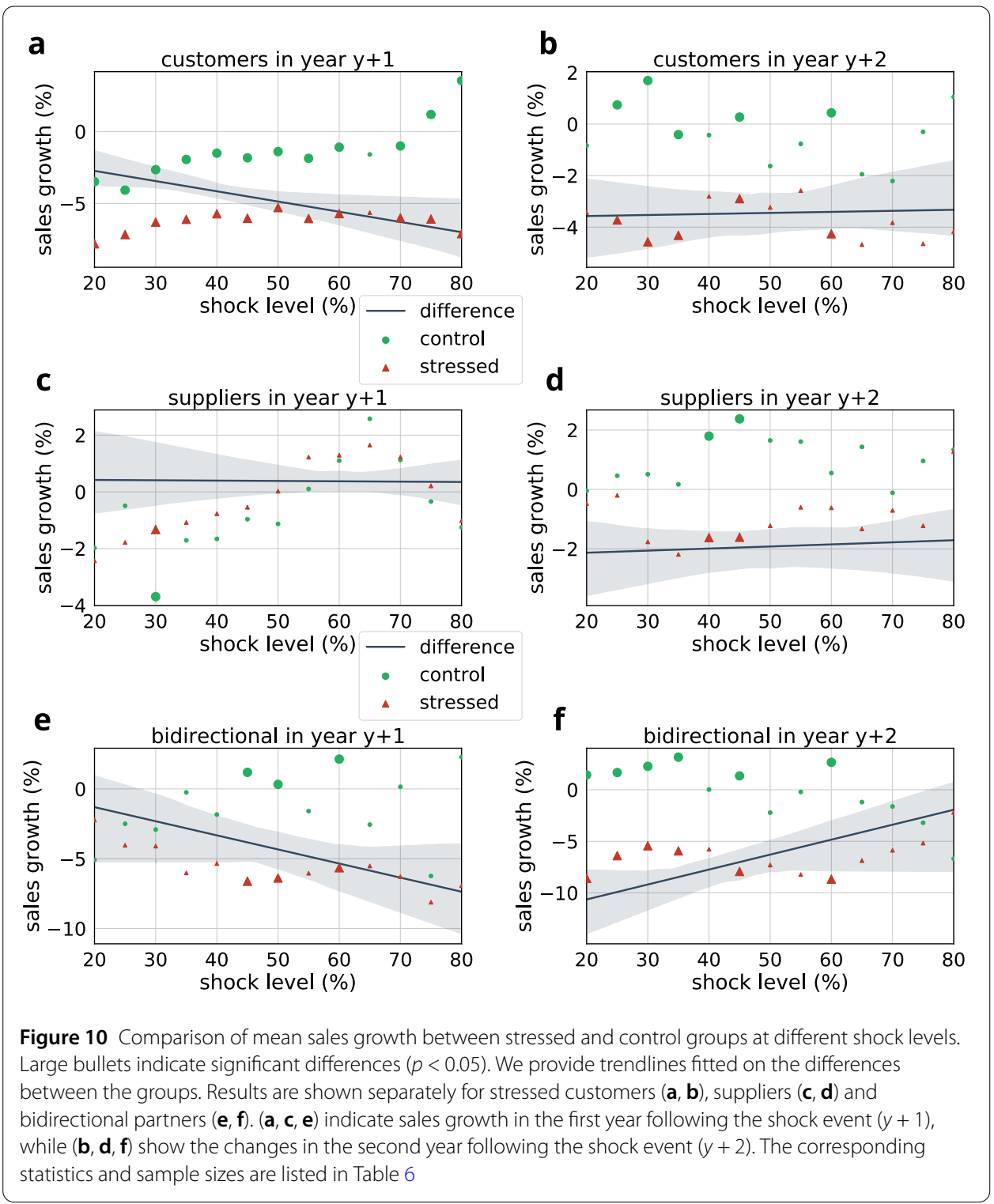

ture bankruptcy. Moreover the company's sales $(\beta=-0.275, p<0.01)$ is also predictive of bankruptcy and companies with higher sales are less likely to go bankrupt. The number of customers $(\beta=0.173, p<0.001)$ is positively associated with the bankruptcy, while the number of suppliers does not significantly impact the outcome. The sales growth does not have a significant effect in the model. Some sectors of the industry categories seem to be significantly predictive of bankruptcy, which is in line with the previous literature showing that the production sectors are at higher risk of becoming bankrupt (for a detailed review of the sector based analysis see [22]). Altogether these results are in line with the findings of our match-paired experiment and further confirm the impact of both shock and stress on bankruptcy.

\subsection{Impact of stress on future sales performance}

We compare the future sales performance of stressed companies to their matched controls' performance. Our results are summarized in Fig. 10 and Table 6. For stressed customers, 
Table 6 Comparison of the sales growth between stressed and control groups at different shock levels. Results are shown separately for stressed customers, suppliers and bidirectional partners in the first and second years following the shock event. We provide sample sizes $(N)$, group means and standard deviations, t-statistics and corresponding $p$-values of independent t-tests between the groups

\begin{tabular}{|c|c|c|c|c|c|c|c|}
\hline $\begin{array}{l}\text { Stress level } \\
\text { drop in sales (\%) }\end{array}$ & Edge type & Year & $N$ & $\begin{array}{l}\text { Stressed } \\
\text { mean } \pm S D\end{array}$ & $\begin{array}{l}\text { Control } \\
\text { mean } \pm \text { SD }\end{array}$ & t-value & $p$-value \\
\hline 20 & customers & 1 & 977 & $-7.80 \pm 28.19$ & $-3.48 \pm 26.97$ & $3.46 \mathrm{e}+00$ & $5.48 \mathrm{e}-04 *$ \\
\hline 25 & customers & 1 & 925 & $-7.16 \pm 28.57$ & $-4.07 \pm 27.04$ & $2.39 \mathrm{e}+00$ & $1.71 \mathrm{e}-02 *$ \\
\hline 30 & customers & 1 & 919 & $-6.29 \pm 28.17$ & $-2.65 \pm 28.26$ & $2.77 \mathrm{e}+00$ & $5.75 e-03 *$ \\
\hline 35 & customers & 1 & 866 & $-6.10 \pm 28.05$ & $-1.94 \pm 27.76$ & $3.10 \mathrm{e}+00$ & $1.96 \mathrm{e}-03 *$ \\
\hline 40 & customers & 1 & 792 & $-5.71 \pm 26.56$ & $-1.50 \pm 28.32$ & $3.05 e+00$ & $2.34 \mathrm{e}-03 *$ \\
\hline 45 & customers & 1 & 718 & $-6.02 \pm 26.83$ & $-1.83 \pm 26.37$ & $2.99 e+00$ & $2.87 \mathrm{e}-03 *$ \\
\hline 50 & customers & 1 & 614 & $-5.28 \pm 27.57$ & $-1.39 \pm 26.66$ & $2.51 \mathrm{e}+00$ & $1.21 \mathrm{e}-02 *$ \\
\hline 55 & customers & 1 & 509 & $-6.04 \pm 27.76$ & $-1.86 \pm 26.53$ & $2.45 e+00$ & $1.43 \mathrm{e}-02 *$ \\
\hline 60 & customers & 1 & 408 & $-5.70 \pm 28.56$ & $-1.09 \pm 25.00$ & $2.45 e+00$ & $1.44 \mathrm{e}-02 *$ \\
\hline 65 & customers & 1 & 338 & $-5.63 \pm 28.28$ & $-1.59 \pm 26.10$ & $1.93 e+00$ & $5.40 \mathrm{e}-02$ \\
\hline 70 & customers & 1 & 299 & $-5.99 \pm 28.15$ & $-1.00 \pm 24.01$ & $2.33 e+00$ & $2.00 \mathrm{e}-02 *$ \\
\hline 75 & customers & 1 & 236 & $-6.08 \pm 28.02$ & $1.19 \pm 27.88$ & $2.82 \mathrm{e}+00$ & $4.98 \mathrm{e}-03 *$ \\
\hline 80 & customers & 1 & 168 & $-7.09 \pm 26.85$ & $3.54 \pm 25.76$ & $3.70 \mathrm{e}+00$ & $2.49 \mathrm{e}-04 *$ \\
\hline 20 & customers & 2 & 977 & $-3.43 \pm 31.54$ & $-0.83 \pm 27.68$ & $1.94 \mathrm{e}+00$ & $5.25 \mathrm{e}-02$ \\
\hline 25 & customers & 2 & 925 & $-3.72 \pm 31.70$ & $0.74 \pm 27.68$ & $3.23 e+00$ & $1.27 \mathrm{e}-03 *$ \\
\hline 30 & customers & 2 & 919 & $-4.57 \pm 31.66$ & $1.69 \pm 27.91$ & $4.49 e+00$ & $7.45 \mathrm{e}-06 *$ \\
\hline 35 & customers & 2 & 866 & $-4.32 \pm 32.38$ & $-0.41 \pm 27.72$ & $2.70 e+00$ & $7.01 \mathrm{e}-03 *$ \\
\hline 40 & customers & 2 & 792 & $-2.80 \pm 31.76$ & $-0.43 \pm 27.53$ & $1.59 \mathrm{e}+00$ & $1.12 \mathrm{e}-01$ \\
\hline 45 & customers & 2 & 718 & $-2.89 \pm 32.14$ & $0.27 \pm 28.20$ & $1.98 \mathrm{e}+00$ & $4.74 \mathrm{e}-02 *$ \\
\hline 50 & customers & 2 & 614 & $-3.23 \pm 32.85$ & $-1.63 \pm 25.77$ & $9.51 \mathrm{e}-01$ & $3.42 \mathrm{e}-01$ \\
\hline 55 & customers & 2 & 509 & $-2.58 \pm 33.83$ & $-0.77 \pm 26.64$ & $9.51 \mathrm{e}-01$ & $3.42 \mathrm{e}-01$ \\
\hline 60 & customers & 2 & 408 & $-4.26 \pm 35.42$ & $0.44 \pm 26.71$ & $2.14 \mathrm{e}+00$ & $3.28 \mathrm{e}-02 *$ \\
\hline 65 & customers & 2 & 338 & $-4.68 \pm 35.59$ & $-1.95 \pm 27.60$ & $1.11 \mathrm{e}+00$ & $2.65 e-01$ \\
\hline 70 & customers & 2 & 299 & $-3.83 \pm 35.76$ & $-2.21 \pm 27.23$ & $6.23 e-01$ & $5.34 \mathrm{e}-01$ \\
\hline 75 & customers & 2 & 236 & $-4.65 \pm 35.27$ & $-0.30 \pm 29.34$ & $1.46 \mathrm{e}+00$ & $1.46 \mathrm{e}-01$ \\
\hline 80 & customers & 2 & 168 & $-4.17 \pm 34.29$ & $1.05 \pm 25.22$ & $1.59 \mathrm{e}+00$ & $1.13 e-01$ \\
\hline 20 & suppliers & 1 & 996 & $-2.43 \pm 27.34$ & $-1.98 \pm 24.63$ & $3.88 \mathrm{e}-01$ & $6.98 \mathrm{e}-01$ \\
\hline 25 & suppliers & 1 & 928 & $-1.78 \pm 26.79$ & $-0.49 \pm 25.11$ & $1.07 \mathrm{e}+00$ & $2.84 \mathrm{e}-01$ \\
\hline 30 & suppliers & 1 & 889 & $-1.33 \pm 26.68$ & $-3.70 \pm 23.79$ & $-1.98 \mathrm{e}+00$ & $4.82 \mathrm{e}-02 *$ \\
\hline 35 & suppliers & 1 & 825 & $-1.08 \pm 26.78$ & $-1.71 \pm 24.57$ & $-4.99 \mathrm{e}-01$ & $6.18 \mathrm{e}-01$ \\
\hline 40 & suppliers & 1 & 721 & $-0.77 \pm 26.33$ & $-1.66 \pm 25.97$ & $-6.47 \mathrm{e}-01$ & $5.18 \mathrm{e}-01$ \\
\hline 45 & suppliers & 1 & 635 & $-0.54 \pm 26.16$ & $-0.97 \pm 24.28$ & $-2.98 \mathrm{e}-01$ & $7.65 e-01$ \\
\hline 50 & suppliers & 1 & 562 & $0.03 \pm 25.31$ & $-1.13 \pm 24.60$ & $-7.78 \mathrm{e}-01$ & $4.37 \mathrm{e}-01$ \\
\hline 55 & suppliers & 1 & 483 & $1.23 \pm 25.10$ & $0.10 \pm 24.67$ & $-7.01 \mathrm{e}-01$ & $4.84 \mathrm{e}-01$ \\
\hline 60 & suppliers & 1 & 420 & $1.29 \pm 24.73$ & $1.10 \pm 22.64$ & $-1.18 \mathrm{e}-01$ & $9.06 \mathrm{e}-01$ \\
\hline 65 & suppliers & 1 & 378 & $1.65 \pm 26.66$ & $2.58 \pm 24.06$ & $5.02 \mathrm{e}-01$ & $6.16 \mathrm{e}-01$ \\
\hline 70 & suppliers & 1 & 320 & $1.23 \pm 27.05$ & $1.13 \pm 26.89$ & $-4.84 \mathrm{e}-02$ & $9.61 \mathrm{e}-01$ \\
\hline 75 & suppliers & 1 & 273 & $0.21 \pm 26.59$ & $-0.34 \pm 27.20$ & $-2.39 \mathrm{e}-01$ & $8.11 \mathrm{e}-01$ \\
\hline 80 & suppliers & 1 & 184 & $-1.02 \pm 23.55$ & $-1.25 \pm 26.26$ & $-9.09 \mathrm{e}-02$ & $9.28 \mathrm{e}-01$ \\
\hline 20 & suppliers & 2 & 996 & $-0.47 \pm 29.74$ & $-0.05 \pm 24.21$ & $3.52 \mathrm{e}-01$ & $7.25 \mathrm{e}-01$ \\
\hline 25 & suppliers & 2 & 928 & $-0.20 \pm 28.96$ & $0.46 \pm 24.76$ & $5.26 \mathrm{e}-01$ & $5.99 \mathrm{e}-01$ \\
\hline 30 & suppliers & 2 & 889 & $-1.76 \pm 29.88$ & $0.51 \pm 25.73$ & $1.72 \mathrm{e}+00$ & $8.57 \mathrm{e}-02$ \\
\hline 35 & suppliers & 2 & 825 & $-2.19 \pm 29.06$ & $0.17 \pm 24.76$ & $1.77 \mathrm{e}+00$ & $7.63 e-02$ \\
\hline 40 & suppliers & 2 & 721 & $-1.62 \pm 29.88$ & $1.79 \pm 27.13$ & $2.27 \mathrm{e}+00$ & $2.32 \mathrm{e}-02 *$ \\
\hline 45 & suppliers & 2 & 635 & $-1.61 \pm 30.12$ & $2.38 \pm 26.01$ & $2.52 \mathrm{e}+00$ & $1.17 \mathrm{e}-02 *$ \\
\hline 50 & suppliers & 2 & 562 & $-1.22 \pm 29.71$ & $1.65 \pm 26.95$ & $1.70 \mathrm{e}+00$ & $9.01 \mathrm{e}-02$ \\
\hline 55 & suppliers & 2 & 483 & $-0.60 \pm 28.43$ & $1.61 \pm 25.51$ & $1.27 \mathrm{e}+00$ & $2.04 \mathrm{e}-01$ \\
\hline 60 & suppliers & 2 & 420 & $-0.62 \pm 28.05$ & $0.55 \pm 24.84$ & $6.39 \mathrm{e}-01$ & $5.23 \mathrm{e}-01$ \\
\hline 65 & suppliers & 2 & 378 & $-1.33 \pm 29.76$ & $1.43 \pm 25.85$ & $1.36 e+00$ & $1.74 \mathrm{e}-01$ \\
\hline 70 & suppliers & 2 & 320 & $-0.70 \pm 28.53$ & $-0.11 \pm 24.35$ & $2.82 \mathrm{e}-01$ & $7.78 \mathrm{e}-01$ \\
\hline 75 & suppliers & 2 & 273 & $-1.22 \pm 29.87$ & $0.96 \pm 24.06$ & $9.39 \mathrm{e}-01$ & $3.48 \mathrm{e}-01$ \\
\hline 80 & suppliers & 2 & 184 & $1.28 \pm 26.44$ & $1.34 \pm 24.17$ & $2.33 \mathrm{e}-02$ & $9.81 \mathrm{e}-01$ \\
\hline 20 & bidirectional & 1 & 159 & $-2.23 \pm 26.23$ & $-5.08 \pm 22.37$ & $-1.04 \mathrm{e}+00$ & $2.97 \mathrm{e}-01$ \\
\hline 25 & bidirectional & 1 & 154 & $-4.04 \pm 28.64$ & $-2.50 \pm 23.17$ & $5.18 \mathrm{e}-01$ & $6.05 e-01$ \\
\hline 30 & bidirectional & 1 & 142 & $-4.10 \pm 29.32$ & $-2.91 \pm 19.59$ & $4.00 \mathrm{e}-01$ & $6.89 \mathrm{e}-01$ \\
\hline 35 & bidirectional & 1 & 135 & $-6.01 \pm 30.46$ & $-0.25 \pm 21.06$ & $1.81 \mathrm{e}+00$ & $7.15 e-02$ \\
\hline
\end{tabular}


Table 6 (Continued)

\begin{tabular}{lllrlrll}
\hline $\begin{array}{l}\text { Stress level } \\
\text { drop in sales (\%) }\end{array}$ & Edge type & Year & $N$ & $\begin{array}{l}\text { Stressed } \\
\text { mean } \pm \text { SD }\end{array}$ & \multicolumn{1}{l}{$\begin{array}{l}\text { Control } \\
\text { mean } \pm \text { SD }\end{array}$} & t-value & $p$-value \\
\hline 40 & bidirectional & 1 & 135 & $-5.35 \pm 28.78$ & $-1.84 \pm 18.96$ & $1.18 \mathrm{e}+00$ & $2.38 \mathrm{e}-01$ \\
45 & bidirectional & 1 & 119 & $-6.61 \pm 26.59$ & $1.19 \pm 23.80$ & $2.38 \mathrm{e}+00$ & $1.79 \mathrm{e}-02 *$ \\
50 & bidirectional & 1 & 102 & $-6.38 \pm 26.31$ & $0.32 \pm 20.75$ & $2.02 \mathrm{e}+00$ & $4.46 \mathrm{e}-02 *$ \\
55 & bidirectional & 1 & 92 & $-6.04 \pm 28.77$ & $-1.59 \pm 23.32$ & $1.15 \mathrm{e}+00$ & $2.51 \mathrm{e}-01$ \\
60 & bidirectional & 1 & 86 & $-5.65 \pm 27.51$ & $2.13 \pm 20.33$ & $2.11 \mathrm{e}+00$ & $3.63 \mathrm{e}-02 *$ \\
65 & bidirectional & 1 & 77 & $-5.52 \pm 26.50$ & $-2.56 \pm 23.30$ & $7.37 \mathrm{e}-01$ & $4.62 \mathrm{e}-01$ \\
70 & bidirectional & 1 & 69 & $-6.29 \pm 28.49$ & $0.15 \pm 24.70$ & $1.42 \mathrm{e}+00$ & $1.58 \mathrm{e}-01$ \\
75 & bidirectional & 1 & 57 & $-8.12 \pm 30.44$ & $-6.24 \pm 24.03$ & $3.66 \mathrm{e}-01$ & $7.15 \mathrm{e}-01$ \\
80 & bidirectional & 1 & 50 & $-6.93 \pm 31.32$ & $2.28 \pm 25.85$ & $1.60 \mathrm{e}+00$ & $1.12 \mathrm{e}-01$ \\
20 & bidirectional & 2 & 159 & $-8.60 \pm 30.35$ & $1.45 \pm 20.51$ & $3.46 \mathrm{e}+00$ & $6.23 \mathrm{e}-04 *$ \\
25 & bidirectional & 2 & 154 & $-6.39 \pm 32.65$ & $1.67 \pm 22.25$ & $2.53 \mathrm{e}+00$ & $1.19 \mathrm{e}-02 *$ \\
30 & bidirectional & 2 & 142 & $-5.43 \pm 33.10$ & $2.27 \pm 25.53$ & $2.20 \mathrm{e}+00$ & $2.89 \mathrm{e}-02 *$ \\
35 & bidirectional & 2 & 135 & $-5.93 \pm 33.16$ & $3.17 \pm 24.70$ & $2.55 \mathrm{e}+00$ & $1.12 \mathrm{e}-02 *$ \\
40 & bidirectional & 2 & 135 & $-5.77 \pm 31.69$ & $0.02 \pm 22.53$ & $1.73 \mathrm{e}+00$ & $8.46 \mathrm{e}-02$ \\
45 & bidirectional & 2 & 119 & $-7.92 \pm 31.40$ & $1.35 \pm 20.62$ & $2.69 \mathrm{e}+00$ & $7.64 \mathrm{e}-03 *$ \\
50 & bidirectional & 2 & 102 & $-7.30 \pm 30.98$ & $-2.22 \pm 28.78$ & $1.21 \mathrm{e}+00$ & $2.26 \mathrm{e}-01$ \\
55 & bidirectional & 2 & 92 & $-8.22 \pm 31.10$ & $-0.21 \pm 26.09$ & $1.89 \mathrm{e}+00$ & $6.01 \mathrm{e}-02$ \\
60 & bidirectional & 2 & 86 & $-8.67 \pm 30.48$ & $2.66 \pm 20.35$ & $2.87 \mathrm{e}+00$ & $4.68 \mathrm{e}-03 *$ \\
65 & bidirectional & 2 & 77 & $-6.87 \pm 29.17$ & $-1.20 \pm 20.28$ & $1.40 \mathrm{e}+00$ & $1.63 \mathrm{e}-01$ \\
70 & bidirectional & 2 & 69 & $-5.87 \pm 29.04$ & $-1.62 \pm 26.87$ & $8.92 \mathrm{e}-01$ & $3.74 \mathrm{e}-01$ \\
75 & bidirectional & 2 & 57 & $-5.17 \pm 29.90$ & $-3.20 \pm 22.86$ & $3.94 \mathrm{e}-01$ & $6.94 \mathrm{e}-01$ \\
80 & bidirectional & 2 & 50 & $-2.19 \pm 31.21$ & $-6.68 \pm 25.15$ & $-7.92 \mathrm{e}-01$ & $4.30 \mathrm{e}-01$ \\
\hline
\end{tabular}

the difference of performance is significant between stressed and control groups nearly at all shock levels (see Fig. 10a) in the follow-up year $y+1$. E.g., at $50 \%$ shock level, $t=2.51$, $p<0.012$. The fitted trend line suggests that the difference increases at larger shock levels. Similar, although not consistent and smaller differences can be observed in the second year after the original shock event (see Fig. 10b). In contrast to the customers, in case of stressed suppliers we have not identified any relevant trend in the group difference (see Figs. 10cd). Finally, in case of bidirectional partners (see Fig. 10e-f) at the first year follow-up the results show a similar trend as seen in the case of stressed customers, however group differences are significant only for certain shock levels (40\%-60\%). The group differences are still very pronounced in the second year follow-up. We must note though that sample sizes for bidirectional partners are an order of magnitude lower than for customers or suppliers (see Table 6).

Next we investigated whether stress results in future shocks and whether shocks show any cascading behavior (see Fig. 11 and Table 7). We calculated in years $y+1$ and $y+2$ the fraction of shocks within the stressed and control groups. Overall, consistent differences can be observed across all three stressed groups both in the first and second years following the shock. Most prominently customers with shocked suppliers are affected (see Fig. 11 b, e.g., at $50 \%$ shock level $\chi^{2}=5.48, p<0.019$ ). The corresponding odds-ratios are shown in Fig. 12.

\subsection{Effect of stress on the production network}

Finally, we analyze the number of new links stressed companies initiate (see Figs. 13, 14 and Tables 8,9). We show the number of new supplier links of stressed and control groups in Fig. 13. As expected, we find that both in the first and second years following the shock, stressed customers seek for more new suppliers (see Fig. 13a-b). For example, at 50\% shock level customers seek in average for 1.05 new suppliers $(D=0.12, p<0.001)$. Al- 


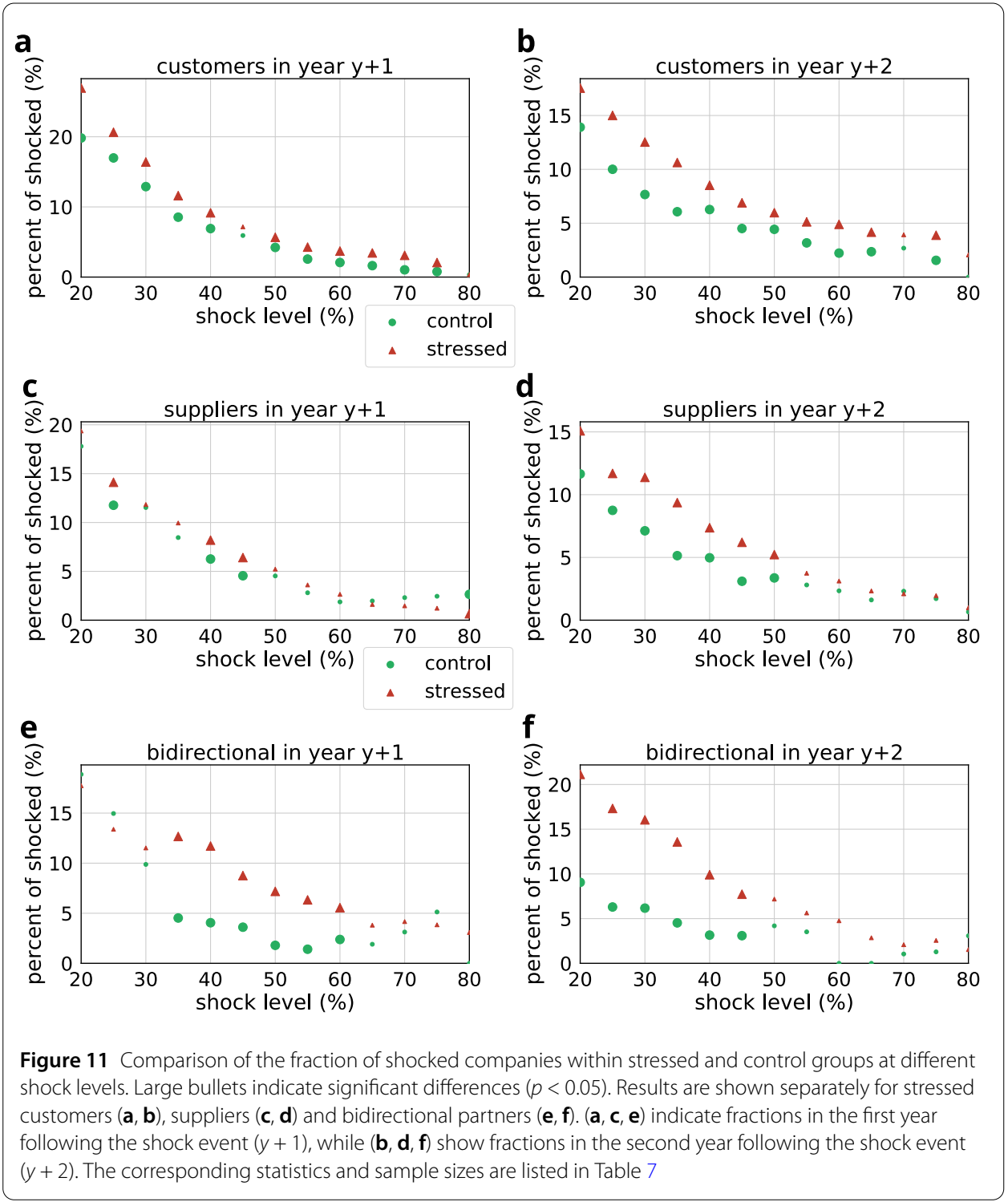

though some of the results are significant for stressed suppliers as well (see Fig. 13c), especially at lower stress levels $(<50 \%)$ suppliers seem to initiate more new supplier relationships than their matched controls. These subtle differences diminish in the second year (all $p>0.05$, see Fig. 13d). Furthermore, we find no significant differences in the network activity of bidirectional partners.

Next we present results in a similar way for new customer links of stressed and control groups in Fig. 14. In the first year follow-up there is no significant difference between stressed and control customers (see Fig. 14a). However, in the second year follow-up stressed customers (between $40 \%$ and $60 \%$ stress level) are initiating more relationships with new customers than matched controls (see Fig. 14b). We find the largest significant differences consistently nearly at all shock levels between the activity of stressed and control suppliers (see Fig. 14c-d) in both the first and second years following the initial shock. In case of bidirectional partners, the results show noticeable differences between groups 
Table 7 Frequency of shocked companies within stressed and control groups at different shock levels. Results are shown separately for stressed customers, suppliers and bidirectional partners in the first and second years following the original shock event. We provide sample sizes $(N)$, frequencies, and the results of $\chi^{2}$ tests with corresponding $p$-values

\begin{tabular}{|c|c|c|c|c|c|c|c|}
\hline $\begin{array}{l}\text { Stress level } \\
\text { drop in sales (\%) }\end{array}$ & Edge type & Year & $N$ & $\begin{array}{l}\text { Shocked (\%) } \\
\text { control }\end{array}$ & $\begin{array}{l}\text { Shocked (\%) } \\
\text { stressed }\end{array}$ & $\chi^{2}(\mathrm{Df}=1)$ & $p$-value \\
\hline 20 & customers & 1 & 1488 & 26.95 & 19.82 & $4.75 e+01$ & $5.48 \mathrm{e}-12 *$ \\
\hline 25 & customers & 1 & 1419 & 20.65 & 16.98 & $1.35 e+01$ & $2.37 \mathrm{e}-04 *$ \\
\hline 30 & customers & 1 & 1396 & 16.40 & 12.89 & $1.53 e+01$ & $9.11 \mathrm{e}-05 *$ \\
\hline 35 & customers & 1 & 1335 & 11.61 & 8.54 & $1.61 \mathrm{e}+01$ & $5.94 \mathrm{e}-05 *$ \\
\hline 40 & customers & 1 & 1244 & 9.16 & 6.91 & $9.79 e+00$ & $1.75 e-03 *$ \\
\hline 45 & customers & 1 & 1131 & 7.16 & 5.92 & $3.11 \mathrm{e}+00$ & $7.78 \mathrm{e}-02$ \\
\hline 50 & customers & 1 & 970 & 5.67 & 4.23 & $4.99 e+00$ & $2.55 \mathrm{e}-02 *$ \\
\hline 55 & customers & 1 & 819 & 4.27 & 2.56 & $9.58 \mathrm{e}+00$ & $1.97 \mathrm{e}-03 *$ \\
\hline 60 & customers & 1 & 674 & 3.71 & 2.08 & $8.83 e+00$ & $2.97 \mathrm{e}-03 *$ \\
\hline 65 & customers & 1 & 552 & 3.44 & 1.63 & $1.13 e+01$ & $7.77 \mathrm{e}-04 *$ \\
\hline 70 & customers & 1 & 484 & 3.10 & 1.03 & $2.02 \mathrm{e}+01$ & $6.94 \mathrm{e}-06 *$ \\
\hline 75 & customers & 1 & 386 & 2.07 & 0.78 & $8.40 \mathrm{e}+00$ & $3.76 \mathrm{e}-03 *$ \\
\hline 80 & customers & 1 & 292 & 0.34 & 0.34 & $0.00 \mathrm{e}+00$ & $1.00 \mathrm{e}+00$ \\
\hline 20 & customers & 2 & 1488 & 17.54 & 13.91 & $1.64 \mathrm{e}+01$ & $5.23 e-05 *$ \\
\hline 25 & customers & 2 & 1419 & 15.01 & 10.01 & $3.94 \mathrm{e}+01$ & $3.37 \mathrm{e}-10 *$ \\
\hline 30 & customers & 2 & 1396 & 12.54 & 7.67 & $4.68 \mathrm{e}+01$ & $7.85 \mathrm{e}-12 *$ \\
\hline 35 & customers & 2 & 1335 & 10.64 & 6.07 & $4.89 \mathrm{e}+01$ & $2.69 \mathrm{e}-12 *$ \\
\hline 40 & customers & 2 & 1244 & 8.52 & 6.27 & $1.07 \mathrm{e}+01$ & $1.06 \mathrm{e}-03 *$ \\
\hline 45 & customers & 2 & 1131 & 6.90 & 4.51 & $1.50 \mathrm{e}+01$ & $1.09 \mathrm{e}-04 *$ \\
\hline 50 & customers & 2 & 970 & 5.98 & 4.43 & $5.48 \mathrm{e}+00$ & $1.93 \mathrm{e}-02 *$ \\
\hline 55 & customers & 2 & 819 & 5.13 & 3.17 & $1.02 e+01$ & $1.43 e-03 *$ \\
\hline 60 & customers & 2 & 674 & 4.90 & 2.23 & $2.21 \mathrm{e}+01$ & $2.60 \mathrm{e}-06 *$ \\
\hline 65 & customers & 2 & 552 & 4.17 & 2.35 & $7.88 \mathrm{e}+00$ & $5.00 \mathrm{e}-03 *$ \\
\hline 70 & customers & 2 & 484 & 3.93 & 2.69 & $2.85 \mathrm{e}+00$ & $9.16 \mathrm{e}-02$ \\
\hline 75 & customers & 2 & 386 & 3.89 & 1.55 & $1.37 \mathrm{e}+01$ & $2.13 \mathrm{e}-04 *$ \\
\hline 80 & customers & 2 & 292 & 2.06 & 0.00 & - & - \\
\hline 20 & suppliers & 1 & 1399 & 19.37 & 17.80 & $2.36 \mathrm{e}+00$ & $1.24 \mathrm{e}-01$ \\
\hline 25 & suppliers & 1 & 1360 & 14.12 & 11.77 & $7.25 e+00$ & $7.08 \mathrm{e}-03 *$ \\
\hline 30 & suppliers & 1 & 1292 & 11.84 & 11.53 & $1.21 \mathrm{e}-01$ & $7.28 \mathrm{e}-01$ \\
\hline 35 & suppliers & 1 & 1206 & 9.95 & 8.46 & $3.47 \mathrm{e}+00$ & $6.25 e-02$ \\
\hline 40 & suppliers & 1 & 1086 & 8.20 & 6.26 & $6.92 \mathrm{e}+00$ & $8.53 e-03 *$ \\
\hline 45 & suppliers & 1 & 967 & 6.41 & 4.55 & $7.71 \mathrm{e}+00$ & $5.48 \mathrm{e}-03 *$ \\
\hline 50 & suppliers & 1 & 861 & 5.23 & 4.53 & $9.67 \mathrm{e}-01$ & $3.25 \mathrm{e}-01$ \\
\hline 55 & suppliers & 1 & 748 & 3.61 & 2.81 & $1.76 e+00$ & $1.84 \mathrm{e}-01$ \\
\hline 60 & suppliers & 1 & 641 & 2.65 & 1.87 & $2.12 \mathrm{e}+00$ & $1.45 \mathrm{e}-01$ \\
\hline 65 & suppliers & 1 & 558 & 1.61 & 1.97 & $3.71 \mathrm{e}-01$ & $5.42 \mathrm{e}-01$ \\
\hline 70 & suppliers & 1 & 476 & 1.47 & 2.31 & $1.49 \mathrm{e}+00$ & $2.22 \mathrm{e}-01$ \\
\hline 75 & suppliers & 1 & 408 & 1.23 & 2.45 & $2.56 \mathrm{e}+00$ & $1.09 \mathrm{e}-01$ \\
\hline 80 & suppliers & 1 & 302 & 0.66 & 2.65 & $4.62 e+00$ & $3.16 \mathrm{e}-02 *$ \\
\hline 20 & suppliers & 2 & 1399 & 15.08 & 11.65 & $1.60 \mathrm{e}+01$ & $6.34 \mathrm{e}-05 *$ \\
\hline 25 & suppliers & 2 & 1360 & 11.69 & 8.75 & $1.47 \mathrm{e}+01$ & $1.24 \mathrm{e}-04 *$ \\
\hline 30 & suppliers & 2 & 1292 & 11.38 & 7.12 & $3.54 \mathrm{e}+01$ & $2.68 \mathrm{e}-09 *$ \\
\hline 35 & suppliers & 2 & 1206 & 9.37 & 5.14 & $4.42 \mathrm{e}+01$ & $2.93 \mathrm{e}-11 *$ \\
\hline 40 & suppliers & 2 & 1086 & 7.37 & 4.97 & $1.32 \mathrm{e}+01$ & $2.84 \mathrm{e}-04 *$ \\
\hline 45 & suppliers & 2 & 967 & 6.21 & 3.10 & $3.10 \mathrm{e}+01$ & $2.63 \mathrm{e}-08 *$ \\
\hline 50 & suppliers & 2 & 861 & 5.23 & 3.37 & $9.14 \mathrm{e}+00$ & $2.51 \mathrm{e}-03 *$ \\
\hline 55 & suppliers & 2 & 748 & 3.74 & 2.81 & $2.40 \mathrm{e}+00$ & $1.21 \mathrm{e}-01$ \\
\hline 60 & suppliers & 2 & 641 & 3.12 & 2.34 & $1.71 \mathrm{e}+00$ & $1.91 \mathrm{e}-01$ \\
\hline 65 & suppliers & 2 & 558 & 2.33 & 1.61 & $1.81 \mathrm{e}+00$ & $1.79 \mathrm{e}-01$ \\
\hline 70 & suppliers & 2 & 476 & 2.10 & 2.31 & $9.31 \mathrm{e}-02$ & $7.60 \mathrm{e}-01$ \\
\hline 75 & suppliers & 2 & 408 & 1.96 & 1.72 & $1.45 \mathrm{e}-01$ & $7.03 e-01$ \\
\hline 80 & suppliers & 2 & 302 & 0.99 & 0.66 & $5.03 e-01$ & $4.78 \mathrm{e}-01$ \\
\hline 20 & bidirectional & 1 & 265 & 17.74 & 18.87 & $2.22 \mathrm{e}-01$ & $6.38 \mathrm{e}-01$ \\
\hline 25 & bidirectional & 1 & 254 & 13.39 & 14.96 & $4.95 \mathrm{e}-01$ & $4.82 \mathrm{e}-01$ \\
\hline 30 & bidirectional & 1 & 243 & 11.52 & 9.88 & $7.40 \mathrm{e}-01$ & $3.90 \mathrm{e}-01$ \\
\hline 35 & bidirectional & 1 & 221 & 12.67 & 4.53 & $3.39 \mathrm{e}+01$ & $5.70 \mathbf{e}-09 *$ \\
\hline 40 & bidirectional & 1 & 222 & 11.71 & 4.05 & $3.35 \mathrm{e}+01$ & $7.24 \mathrm{e}-09 *$ \\
\hline
\end{tabular}


Table 7 (Continued)

\begin{tabular}{|c|c|c|c|c|c|c|c|}
\hline $\begin{array}{l}\text { Stress level } \\
\text { drop in sales (\%) }\end{array}$ & Edge type & Year & $N$ & $\begin{array}{l}\text { Shocked (\%) } \\
\text { control }\end{array}$ & $\begin{array}{l}\text { Shocked (\%) } \\
\text { stressed }\end{array}$ & $\chi^{2}(\mathrm{Df}=1)$ & $p$-value \\
\hline 45 & bidirectional & 1 & 194 & 8.76 & 3.61 & $1.48 \mathrm{e}+01$ & $1.18 \mathrm{e}-04 *$ \\
\hline 50 & bidirectional & 1 & 167 & 7.19 & 1.80 & $2.75 e+01$ & $1.58 \mathrm{e}-07 *$ \\
\hline 55 & bidirectional & 1 & 142 & 6.34 & 1.41 & $2.49 e+01$ & $6.20 \mathrm{e}-07 *$ \\
\hline 60 & bidirectional & 1 & 126 & 5.56 & 2.38 & $5.46 e+00$ & $1.94 \mathrm{e}-02 *$ \\
\hline 65 & bidirectional & 1 & 105 & 3.81 & 1.91 & $2.04 \mathrm{e}+00$ & $1.53 \mathrm{e}-01$ \\
\hline 70 & bidirectional & 1 & 96 & 4.17 & 3.12 & $3.44 \mathrm{e}-01$ & $5.57 \mathrm{e}-01$ \\
\hline 75 & bidirectional & 1 & 78 & 3.85 & 5.13 & $2.64 \mathrm{e}-01$ & $6.08 \mathrm{e}-01$ \\
\hline 80 & bidirectional & 1 & 65 & 3.08 & 0.00 & - & - \\
\hline 20 & bidirectional & 2 & 265 & 21.13 & 9.06 & $4.69 \mathrm{e}+01$ & $7.41 \mathrm{e}-12 *$ \\
\hline 25 & bidirectional & 2 & 254 & 17.32 & 6.30 & $5.23 e+01$ & $4.78 \mathrm{e}-13 *$ \\
\hline 30 & bidirectional & 2 & 243 & 16.05 & 6.17 & $4.09 e+01$ & $1.58 \mathrm{e}-10 *$ \\
\hline 35 & bidirectional & 2 & 221 & 13.57 & 4.53 & $4.19 \mathrm{e}+01$ & $9.63 \mathrm{e}-11 *$ \\
\hline 40 & bidirectional & 2 & 222 & 9.91 & 3.15 & $3.32 \mathrm{e}+01$ & $8.36 \mathrm{e}-09 *$ \\
\hline 45 & bidirectional & 2 & 194 & 7.73 & 3.09 & $1.39 \mathrm{e}+01$ & $1.90 \mathrm{e}-04 *$ \\
\hline 50 & bidirectional & 2 & 167 & 7.19 & 4.19 & $3.73 e+00$ & $5.35 \mathrm{e}-02$ \\
\hline 55 & bidirectional & 2 & 142 & 5.63 & 3.52 & $1.87 \mathrm{e}+00$ & $1.72 \mathrm{e}-01$ \\
\hline 60 & bidirectional & 2 & 126 & 4.76 & 0.00 & - & - \\
\hline 65 & bidirectional & 2 & 105 & 2.86 & 0.00 & - & - \\
\hline 70 & bidirectional & 2 & 96 & 2.08 & 1.04 & $1.01 \mathrm{e}+00$ & $3.15 \mathrm{e}-01$ \\
\hline 75 & bidirectional & 2 & 78 & 2.56 & 1.28 & $1.01 \mathrm{e}+00$ & $3.14 \mathrm{e}-01$ \\
\hline 80 & bidirectional & 2 & 65 & 1.54 & 3.08 & $5.16 \mathrm{e}-01$ & $4.73 e-01$ \\
\hline
\end{tabular}

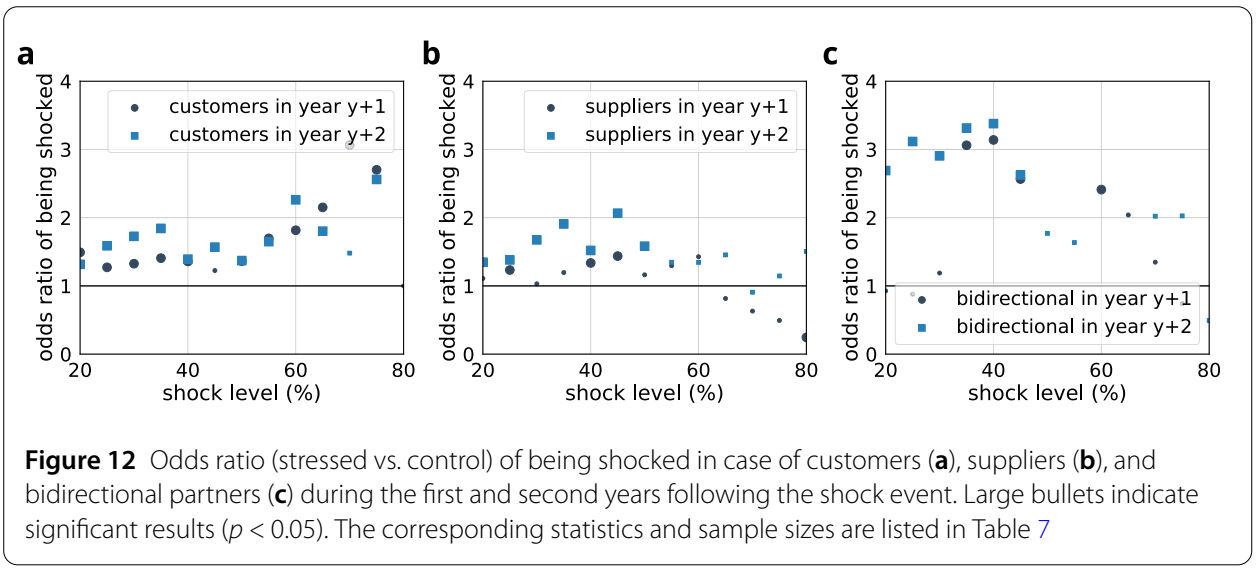

at certain shock levels $(<60 \%)$. Taken together, the results indicate a more intense activity in the stress group than in the control group in terms of new links.

Finally, our results indicate that $14.8 \%$ of the new supplier links initiated in year $y+1$ of stressed customers have a matching industry label to the shocked neighbor. The same percentage is $19.8 \%$ in year $y+2$. The similar quantities for stressed suppliers looking for new customers are $18.3 \%(y+1)$ and $24.1 \%(y+2)$, respectively. These overlaps are considerably large and suggest that new links are often "replacements" and stressed partners quickly react to shocks within the production network.

\section{Discussion and conclusion}

The current study explores the impact of shocks in the production network. We examined a unique dataset containing temporal information on companies for an 8 year period from Slovenia. We found that economic partners of shocked companies have a higher chance of going bankrupt, even if they do not show signs of performance loss at the time of the 


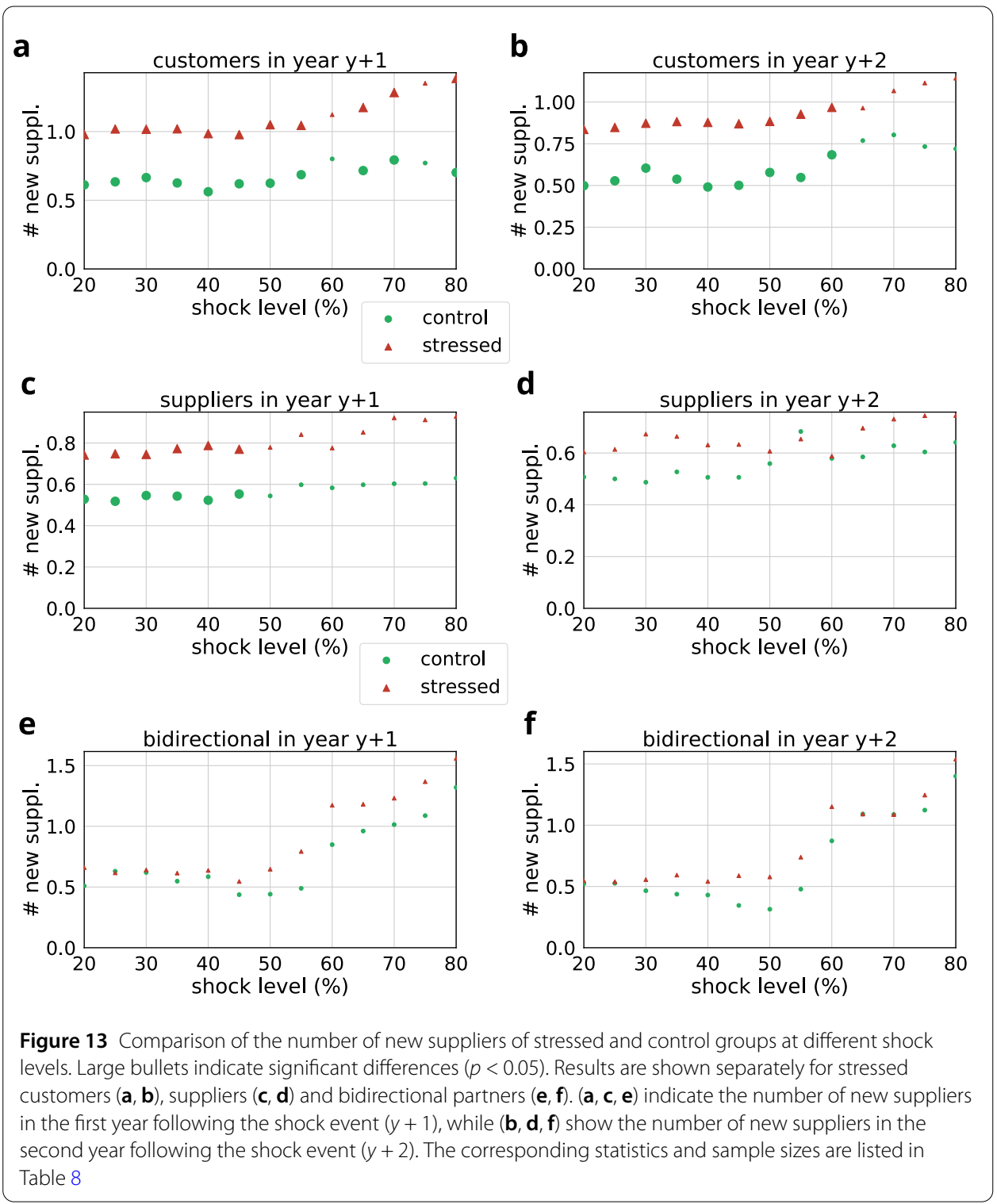

shocking event. These results suggest that not only sales shocks, but the shock induced stress is related to bankruptcy. It is important to highlight that besides these, other factors including the sales performance, the number of customers, and the industry sector significantly impact the likelihood of future bankruptcy as seen in our logistic regression based results. These findings are in line with previous reports [2, 22].

We hypothesized that stressed companies experience loss in performance in the followup years. Our results support this hypothesis. Specifically, we found that stressed customers show a significant drop in sales compared to control companies. However, compared to the stressed customers, suppliers appear to be more resilient to the shock induced stress in terms of sales performance. Bidirectional relationships are more stable in the first year follow-up, while their performance seems to be heavily impacted in the second year. This might reflect a temporal shift in the impact of shock on mutually dependent partnerships. We note that bidirectional partnerships represent a complex form of economical interactions and give place to the interplay of multiple network effects. Detailed analy- 


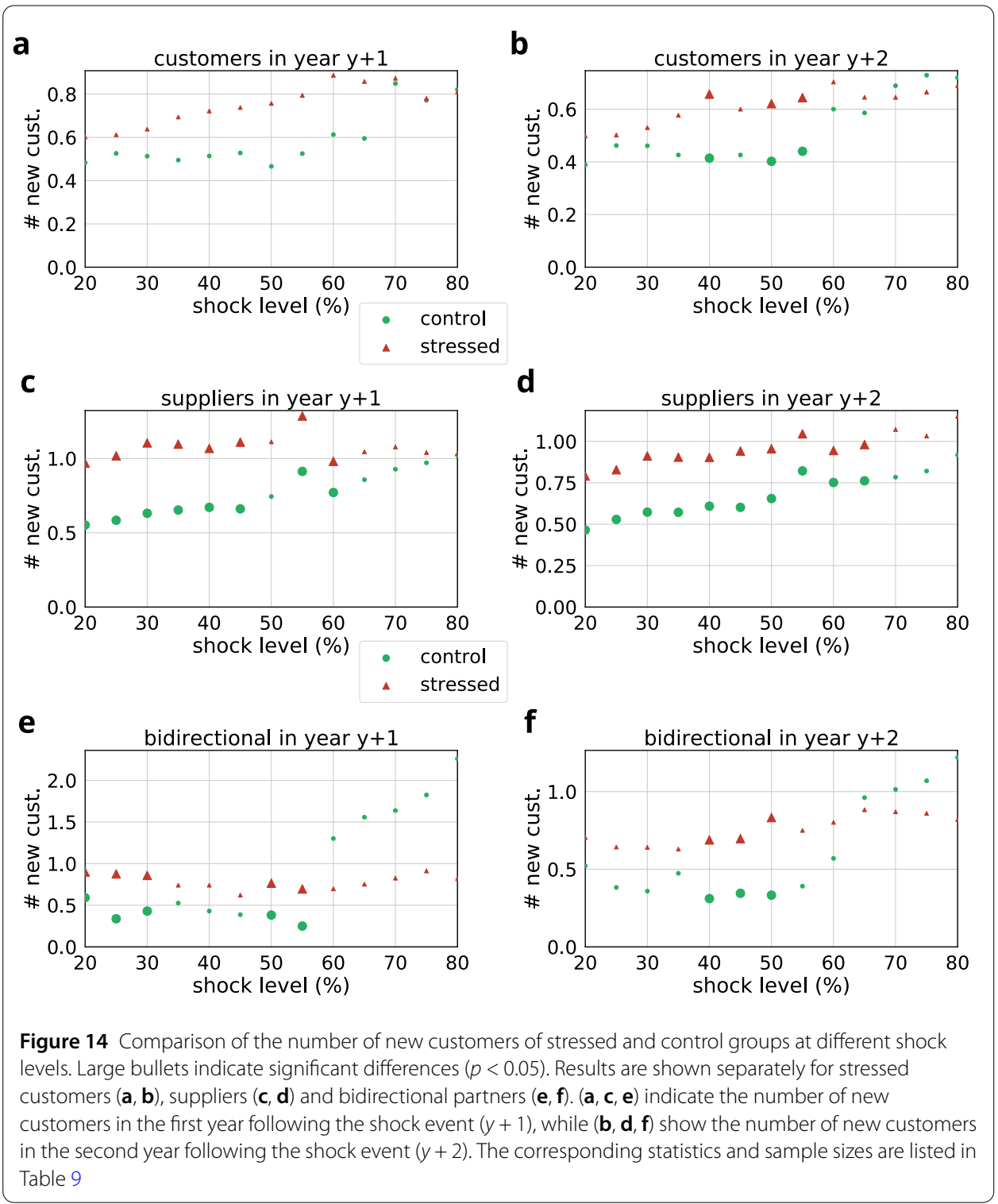

sis of the bidirectional partnerships is out of the scope of the current study, however the increased likelihood of being shocked in this category with the above mentioned performance stability raises important questions for future experiments.

The result that stress frequently leads to shock, makes it likely that there is a shock spill over to other neighbors in the network. These results are in line with [2], where the authors examined the customers of suppliers hit by a natural disaster, and reported that firm-level shocks propagate within production networks.

Regarding the stress induced reconfiguration of the network we hypothesized that the tense urges the stressed party to replace the problematic partner. More specifically, we expected that companies' new partnership seeking would vary according to their relationship with the shocked neighbor. In line with our expectations customers of the shocked node initiated more new partnerships with suppliers, and suppliers improved the numbers of their customers consistently for at least two years. Furthermore, we found that these new links often share the industry sector of the initially shocked node and hence 
Table 8 Comparison of the number of new suppliers of stressed and control groups at different shock levels. Results are shown separately for stressed customers, suppliers and bidirectional partners in the first and second years following the original shock event. We provide sample sizes $(N)$, mean number of new customers, and the results of Kolmogorov-Smirnov tests with corresponding $p$-values

\begin{tabular}{|c|c|c|c|c|c|c|c|}
\hline Stress level & Edge type & Year & $N$ & Stressed & Control & D & $p$-value \\
\hline 20 & customers & 1 & 977 & 0.98 & 0.61 & $1.31 \mathrm{e}-01$ & $1.00 \mathrm{e}-07 *$ \\
\hline 25 & customers & 1 & 925 & 1.02 & 0.63 & $1.41 \mathrm{e}-01$ & $2.21 \mathrm{e}-08 *$ \\
\hline 30 & customers & 1 & 919 & 1.02 & 0.67 & $1.19 \mathrm{e}-01$ & $4.74 \mathrm{e}-06 *$ \\
\hline 35 & customers & 1 & 866 & 1.02 & 0.63 & $1.50 \mathrm{e}-01$ & $6.29 \mathrm{e}-09 *$ \\
\hline 40 & customers & 1 & 792 & 0.98 & 0.56 & $1.26 \mathrm{e}-01$ & $6.40 \mathrm{e}-06 *$ \\
\hline 45 & customers & 1 & 718 & 0.98 & 0.62 & $1.16 \mathrm{e}-01$ & $1.34 \mathrm{e}-04 *$ \\
\hline 50 & customers & 1 & 614 & 1.05 & 0.62 & $1.21 \mathrm{e}-01$ & $2.64 \mathrm{e}-04 *$ \\
\hline 55 & customers & 1 & 509 & 1.04 & 0.69 & $1.20 \mathrm{e}-01$ & $1.32 \mathrm{e}-03 *$ \\
\hline 60 & customers & 1 & 408 & 1.12 & 0.80 & $9.31 \mathrm{e}-02$ & $5.80 \mathrm{e}-02$ \\
\hline 65 & customers & 1 & 338 & 1.18 & 0.72 & $1.15 \mathrm{e}-01$ & $2.21 \mathrm{e}-02 *$ \\
\hline 70 & customers & 1 & 299 & 1.28 & 0.79 & $1.27 \mathrm{e}-01$ & $1.59 \mathrm{e}-02 *$ \\
\hline 75 & customers & 1 & 236 & 1.35 & 0.77 & $1.06 \mathrm{e}-01$ & $1.42 \mathrm{e}-01$ \\
\hline 80 & customers & 1 & 168 & 1.39 & 0.70 & $1.55 \mathrm{e}-01$ & $3.56 \mathrm{e}-02 *$ \\
\hline 20 & customers & 2 & 977 & 0.84 & 0.50 & $1.36 \mathrm{e}-01$ & $2.62 \mathrm{e}-08 *$ \\
\hline 25 & customers & 2 & 925 & 0.85 & 0.53 & $1.20 \mathrm{e}-01$ & $3.20 \mathrm{e}-06 *$ \\
\hline 30 & customers & 2 & 919 & 0.87 & 0.60 & $1.15 \mathrm{e}-01$ & $9.60 \mathrm{e}-06 *$ \\
\hline 35 & customers & 2 & 866 & 0.88 & 0.54 & $1.43 e-01$ & $3.70 \mathrm{e}-08 *$ \\
\hline 40 & customers & 2 & 792 & 0.88 & 0.49 & $1.64 \mathrm{e}-01$ & $9.95 \mathrm{e}-10 *$ \\
\hline 45 & customers & 2 & 718 & 0.87 & 0.50 & $1.14 \mathrm{e}-01$ & $1.69 \mathrm{e}-04 *$ \\
\hline 50 & customers & 2 & 614 & 0.88 & 0.58 & $8.63 \mathrm{e}-02$ & $2.06 \mathrm{e}-02 *$ \\
\hline 55 & customers & 2 & 509 & 0.93 & 0.55 & $1.47 \mathrm{e}-01$ & $3.08 \mathrm{e}-05 *$ \\
\hline 60 & customers & 2 & 408 & 0.97 & 0.68 & $1.18 \mathrm{e}-01$ & $7.01 \mathrm{e}-03 *$ \\
\hline 65 & customers & 2 & 338 & 0.96 & 0.77 & $7.10 \mathrm{e}-02$ & $3.62 \mathrm{e}-01$ \\
\hline 70 & customers & 2 & 299 & 1.07 & 0.80 & $8.03 \mathrm{e}-02$ & $2.91 \mathrm{e}-01$ \\
\hline 75 & customers & 2 & 236 & 1.11 & 0.73 & $8.05 \mathrm{e}-02$ & $4.30 \mathrm{e}-01$ \\
\hline 80 & customers & 2 & 168 & 1.14 & 0.72 & $1.07 \mathrm{e}-01$ & $2.90 \mathrm{e}-01$ \\
\hline 20 & suppliers & 1 & 996 & 0.74 & 0.53 & $8.13 e-02$ & $2.74 \mathrm{e}-03 *$ \\
\hline 25 & suppliers & 1 & 928 & 0.75 & 0.52 & $9.48 \mathrm{e}-02$ & $4.71 \mathrm{e}-04 *$ \\
\hline 30 & suppliers & 1 & 889 & 0.74 & 0.55 & $6.75 e-02$ & $3.48 \mathrm{e}-02 *$ \\
\hline 35 & suppliers & 1 & 825 & 0.77 & 0.54 & $8.12 \mathrm{e}-02$ & $8.65 \mathrm{e}-03 *$ \\
\hline 40 & suppliers & 1 & 721 & 0.79 & 0.52 & $8.46 \mathrm{e}-02$ & $1.14 \mathrm{e}-02 *$ \\
\hline 45 & suppliers & 1 & 635 & 0.77 & 0.55 & $8.03 e-02$ & $3.32 \mathrm{e}-02 *$ \\
\hline 50 & suppliers & 1 & 562 & 0.78 & 0.54 & $7.30 \mathrm{e}-02$ & $1.00 \mathrm{e}-01$ \\
\hline 55 & suppliers & 1 & 483 & 0.84 & 0.60 & $5.38 \mathrm{e}-02$ & $4.86 \mathrm{e}-01$ \\
\hline 60 & suppliers & 1 & 420 & 0.78 & 0.58 & $5.95 e-02$ & $4.47 \mathrm{e}-01$ \\
\hline 65 & suppliers & 1 & 378 & 0.85 & 0.60 & $5.82 \mathrm{e}-02$ & $5.45 \mathrm{e}-01$ \\
\hline 70 & suppliers & 1 & 320 & 0.92 & 0.60 & $7.50 \mathrm{e}-02$ & $3.30 \mathrm{e}-01$ \\
\hline 75 & suppliers & 1 & 273 & 0.91 & 0.60 & $5.86 \mathrm{e}-02$ & $7.37 \mathrm{e}-01$ \\
\hline 80 & suppliers & 1 & 184 & 0.93 & 0.63 & $8.15 \mathrm{e}-02$ & $5.75 \mathrm{e}-01$ \\
\hline 20 & suppliers & 2 & 996 & 0.60 & 0.51 & $2.51 \mathrm{e}-02$ & $9.12 \mathrm{e}-01$ \\
\hline 25 & suppliers & 2 & 928 & 0.61 & 0.50 & $2.91 \mathrm{e}-02$ & $8.27 \mathrm{e}-01$ \\
\hline 30 & suppliers & 2 & 889 & 0.67 & 0.49 & $4.72 \mathrm{e}-02$ & $2.74 \mathrm{e}-01$ \\
\hline 35 & suppliers & 2 & 825 & 0.66 & 0.53 & $4.12 \mathrm{e}-02$ & $4.85 \mathrm{e}-01$ \\
\hline 40 & suppliers & 2 & 721 & 0.63 & 0.51 & $3.74 \mathrm{e}-02$ & $6.93 \mathrm{e}-01$ \\
\hline 45 & suppliers & 2 & 635 & 0.63 & 0.51 & $3.94 \mathrm{e}-02$ & $7.09 \mathrm{e}-01$ \\
\hline 50 & suppliers & 2 & 562 & 0.61 & 0.56 & $1.42 \mathrm{e}-02$ & $1.00 \mathrm{e}+00$ \\
\hline 55 & suppliers & 2 & 483 & 0.65 & 0.68 & $2.90 \mathrm{e}-02$ & $9.87 \mathrm{e}-01$ \\
\hline 60 & suppliers & 2 & 420 & 0.59 & 0.58 & $9.52 \mathrm{e}-03$ & $1.00 \mathrm{e}+00$ \\
\hline 65 & suppliers & 2 & 378 & 0.70 & 0.58 & $2.91 \mathrm{e}-02$ & $9.97 \mathrm{e}-01$ \\
\hline 70 & suppliers & 2 & 320 & 0.73 & 0.63 & $2.19 \mathrm{e}-02$ & $1.00 \mathrm{e}+00$ \\
\hline 75 & suppliers & 2 & 273 & 0.74 & 0.60 & $2.56 \mathrm{e}-02$ & $1.00 \mathrm{e}+00$ \\
\hline 80 & suppliers & 2 & 184 & 0.74 & 0.64 & $4.35 \mathrm{e}-02$ & $9.95 \mathrm{e}-01$ \\
\hline 20 & bidirectional & 1 & 159 & 0.66 & 0.51 & $8.81 \mathrm{e}-02$ & $5.70 \mathrm{e}-01$ \\
\hline 25 & bidirectional & 1 & 154 & 0.62 & 0.63 & $8.44 \mathrm{e}-02$ & $6.44 \mathrm{e}-01$ \\
\hline 30 & bidirectional & 1 & 142 & 0.64 & 0.62 & $7.04 \mathrm{e}-02$ & $8.75 e-01$ \\
\hline 35 & bidirectional & 1 & 135 & 0.61 & 0.55 & $5.19 \mathrm{e}-02$ & $9.94 \mathrm{e}-01$ \\
\hline 40 & bidirectional & 1 & 135 & 0.64 & 0.58 & $4.44 \mathrm{e}-02$ & $9.99 \mathrm{e}-01$ \\
\hline 45 & bidirectional & 1 & 119 & 0.55 & 0.44 & $8.40 \mathrm{e}-02$ & $7.97 \mathrm{e}-01$ \\
\hline
\end{tabular}


Table 8 (Continued)

\begin{tabular}{|c|c|c|c|c|c|c|c|}
\hline Stress level & Edge type & Year & $N$ & Stressed & Control & D & $p$-value \\
\hline 50 & bidirectional & 1 & 102 & 0.65 & 0.44 & $1.47 \mathrm{e}-01$ & $2.21 \mathrm{e}-01$ \\
\hline 55 & bidirectional & 1 & 92 & 0.79 & 0.49 & $1.52 \mathrm{e}-01$ & $2.38 \mathrm{e}-01$ \\
\hline 60 & bidirectional & 1 & 86 & 1.17 & 0.85 & $8.14 \mathrm{e}-02$ & $9.40 \mathrm{e}-01$ \\
\hline 65 & bidirectional & 1 & 77 & 1.18 & 0.96 & $7.79 \mathrm{e}-02$ & $9.75 \mathrm{e}-01$ \\
\hline 70 & bidirectional & 1 & 69 & 1.23 & 1.01 & $1.01 \mathrm{e}-01$ & $8.73 e^{-01}$ \\
\hline 75 & bidirectional & 1 & 57 & 1.37 & 1.09 & $8.77 \mathrm{e}-02$ & $9.82 \mathrm{e}-01$ \\
\hline 80 & bidirectional & 1 & 50 & 1.56 & 1.32 & $6.00 \mathrm{e}-02$ & $1.00 \mathrm{e}+00$ \\
\hline 20 & bidirectional & 2 & 159 & 0.55 & 0.52 & $1.89 \mathrm{e}-02$ & $1.00 \mathrm{e}+00$ \\
\hline 25 & bidirectional & 2 & 154 & 0.54 & 0.53 & $1.30 \mathrm{e}-02$ & $1.00 \mathrm{e}+00$ \\
\hline 30 & bidirectional & 2 & 142 & 0.56 & 0.47 & $4.23 e-02$ & $1.00 \mathrm{e}+00$ \\
\hline 35 & bidirectional & 2 & 135 & 0.59 & 0.44 & $4.44 \mathrm{e}-02$ & $9.99 \mathrm{e}-01$ \\
\hline 40 & bidirectional & 2 & 135 & 0.54 & 0.43 & $3.70 \mathrm{e}-02$ & $1.00 \mathrm{e}+00$ \\
\hline 45 & bidirectional & 2 & 119 & 0.59 & 0.34 & $8.40 \mathrm{e}-02$ & $7.97 \mathrm{e}-01$ \\
\hline 50 & bidirectional & 2 & 102 & 0.58 & 0.31 & $1.57 \mathrm{e}-01$ & $1.63 e-01$ \\
\hline 55 & bidirectional & 2 & 92 & 0.74 & 0.48 & $7.61 \mathrm{e}-02$ & $9.55 \mathrm{e}-01$ \\
\hline 60 & bidirectional & 2 & 86 & 1.15 & 0.87 & $4.65 \mathrm{e}-02$ & $1.00 \mathrm{e}+00$ \\
\hline 65 & bidirectional & 2 & 77 & 1.09 & 1.09 & $1.30 \mathrm{e}-02$ & $1.00 \mathrm{e}+00$ \\
\hline 70 & bidirectional & 2 & 69 & 1.09 & 1.09 & $2.90 \mathrm{e}-02$ & $1.00 \mathrm{e}+00$ \\
\hline 75 & bidirectional & 2 & 57 & 1.25 & 1.12 & $1.05 \mathrm{e}-01$ & $9.14 \mathrm{e}-01$ \\
\hline 80 & bidirectional & 2 & 50 & 1.54 & 1.40 & $1.20 \mathrm{e}-01$ & $8.69 \mathrm{e}-01$ \\
\hline
\end{tabular}

may be potential replacements. Surprisingly, in case of the suppliers we have observed an emphasised seek for new suppliers at lower stress levels. This might be associated with their above presented stress resilience.

\subsection{Limitations and future work}

While the data and our analyses presents various aspects of the production network, we must note their limitations. Foremost, since no performance indicators were available for foreign companies, we investigated the customer-supplier relations within a single country, which decreases the generalizability of the presented results. Furthermore, since companies are required to send all funds over $50 \mathrm{k}$ EUR via the TARGET2 system, the data covers all of the large transactions, but not necessarily all of the smaller transactions that are less than 50k EUR. Some part of the customer-supplier relations may remain uncovered which can lead to an overall underestimation of the effects of stress. Throughout the paper we consider all industry sectors other than governmental and financial services to be part of the production network. Some of the companies within our analyses may not strictly belong to the production network. More information on the companies activities could provide a more precise view of the network itself. Surprisingly, a few of the reported results potentially show trends with the shock threshold, e.g., there is an increasing trend in Fig. 10. Future analyses would be required to validate if these are actual signals or artifacts within the data analyzed.

The data studied is right after the 2008 global financial crisis and therefore we consider this the broad, implicit cause of the disruptions within the nation's economy. Throughout the analyses we study sales drops that are strong indicators of "shocks". However, we do not have explicit information on the specific root cause of shocks.

In this paper we employ a time sensitive, matched pairs quasi-experimental design and the presented analyses correct for confounders such as the company's industry sector, current sales, number of customer and supplier links. There can be additional factors to consider and follow-up analyses with different matching criteria can lead to new discoveries. For example, one could restrict the control group to have at least one connection to 
Table 9 Comparison of the number of new customers of stressed and control groups at different shock levels. Results are shown separately for stressed customers, suppliers and bidirectional partners in the first and second years following the original shock event. We provide sample sizes $(N)$, mean number of new suppliers, and the results of Kolmogorov-Smirnov tests with corresponding $p$-values

\begin{tabular}{|c|c|c|c|c|c|c|c|}
\hline Stress level & Edge type & Year & $N$ & Stressed & Control & D & $p$-value \\
\hline 20 & customers & 1 & 977 & 0.60 & 0.48 & $3.38 \mathrm{e}-02$ & $6.33 e-01$ \\
\hline 25 & customers & 1 & 925 & 0.61 & 0.53 & $2.49 \mathrm{e}-02$ & $9.38 \mathrm{e}-01$ \\
\hline 30 & customers & 1 & 919 & 0.64 & 0.51 & $3.48 \mathrm{e}-02$ & $6.33 \mathrm{e}-01$ \\
\hline 35 & customers & 1 & 866 & 0.69 & 0.49 & $4.04 \mathrm{e}-02$ & $4.79 \mathrm{e}-01$ \\
\hline 40 & customers & 1 & 792 & 0.72 & 0.51 & $4.42 \mathrm{e}-02$ & $4.22 \mathrm{e}-01$ \\
\hline 45 & customers & 1 & 718 & 0.74 & 0.53 & $3.90 \mathrm{e}-02$ & $6.46 e-01$ \\
\hline 50 & customers & 1 & 614 & 0.76 & 0.47 & $5.54 \mathrm{e}-02$ & $3.03 e-01$ \\
\hline 55 & customers & 1 & 509 & 0.79 & 0.53 & $4.91 \mathrm{e}-02$ & $5.72 \mathrm{e}-01$ \\
\hline 60 & customers & 1 & 408 & 0.89 & 0.61 & $5.39 \mathrm{e}-02$ & $5.94 \mathrm{e}-01$ \\
\hline 65 & customers & 1 & 338 & 0.86 & 0.59 & $6.21 \mathrm{e}-02$ & $5.32 \mathrm{e}-01$ \\
\hline 70 & customers & 1 & 299 & 0.87 & 0.85 & $5.02 \mathrm{e}-02$ & $8.47 \mathrm{e}-01$ \\
\hline 75 & customers & 1 & 236 & 0.78 & 0.77 & $2.54 \mathrm{e}-02$ & $1.00 \mathrm{e}+00$ \\
\hline 80 & customers & 1 & 168 & 0.81 & 0.82 & $2.38 \mathrm{e}-02$ & $1.00 e+00$ \\
\hline 20 & customers & 2 & 977 & 0.50 & 0.39 & $4.40 \mathrm{e}-02$ & $3.00 \mathrm{e}-01$ \\
\hline 25 & customers & 2 & 925 & 0.50 & 0.46 & $3.46 \mathrm{e}-02$ & $6.38 \mathrm{e}-01$ \\
\hline 30 & customers & 2 & 919 & 0.53 & 0.46 & $3.70 \mathrm{e}-02$ & $5.56 \mathrm{e}-01$ \\
\hline 35 & customers & 2 & 866 & 0.58 & 0.43 & $5.20 \mathrm{e}-02$ & $1.93 \mathrm{e}-01$ \\
\hline 40 & customers & 2 & 792 & 0.66 & 0.41 & $7.45 \mathrm{e}-02$ & $2.46 \mathrm{e}-02 *$ \\
\hline 45 & customers & 2 & 718 & 0.60 & 0.43 & $5.85 \mathrm{e}-02$ & $1.71 \mathrm{e}-01$ \\
\hline 50 & customers & 2 & 614 & 0.62 & 0.40 & $8.63 e-02$ & $2.06 \mathrm{e}-02 *$ \\
\hline 55 & customers & 2 & 509 & 0.64 & 0.44 & $9.43 e-02$ & $2.16 \mathrm{e}-02 *$ \\
\hline 60 & customers & 2 & 408 & 0.70 & 0.60 & $3.19 \mathrm{e}-02$ & $9.86 \mathrm{e}-01$ \\
\hline 65 & customers & 2 & 338 & 0.65 & 0.59 & $1.18 \mathrm{e}-02$ & $1.00 \mathrm{e}+00$ \\
\hline 70 & customers & 2 & 299 & 0.65 & 0.69 & $2.01 \mathrm{e}-02$ & $1.00 \mathrm{e}+00$ \\
\hline 75 & customers & 2 & 236 & 0.67 & 0.73 & $4.24 \mathrm{e}-02$ & $9.84 \mathrm{e}-01$ \\
\hline 80 & customers & 2 & 168 & 0.69 & 0.72 & $4.17 \mathrm{e}-02$ & $9.99 \mathrm{e}-01$ \\
\hline 20 & suppliers & 1 & 996 & 0.97 & 0.55 & $1.14 \mathrm{e}-01$ & $4.21 \mathrm{e}-06 *$ \\
\hline 25 & suppliers & 1 & 928 & 1.02 & 0.58 & $1.21 \mathrm{e}-01$ & $2.63 \mathrm{e}-06 *$ \\
\hline 30 & suppliers & 1 & 889 & 1.10 & 0.63 & $1.16 \mathrm{e}-01$ & $1.29 \mathrm{e}-05 *$ \\
\hline 35 & suppliers & 1 & 825 & 1.10 & 0.65 & $1.04 \mathrm{e}-01$ & $2.53 \mathrm{e}-04 *$ \\
\hline 40 & suppliers & 1 & 721 & 1.07 & 0.67 & $9.57 \mathrm{e}-02$ & $2.70 \mathrm{e}-03 *$ \\
\hline 45 & suppliers & 1 & 635 & 1.11 & 0.66 & $9.61 \mathrm{e}-02$ & $5.68 \mathrm{e}-03 *$ \\
\hline 50 & suppliers & 1 & 562 & 1.11 & 0.74 & $7.65 \mathrm{e}-02$ & $7.45 \mathrm{e}-02$ \\
\hline 55 & suppliers & 1 & 483 & 1.29 & 0.91 & $8.90 \mathrm{e}-02$ & $4.35 \mathrm{e}-02 *$ \\
\hline 60 & suppliers & 1 & 420 & 0.98 & 0.77 & $1.00 \mathrm{e}-01$ & $2.99 \mathrm{e}-02 *$ \\
\hline 65 & suppliers & 1 & 378 & 1.04 & 0.86 & $9.52 \mathrm{e}-02$ & $6.48 \mathrm{e}-02$ \\
\hline 70 & suppliers & 1 & 320 & 1.08 & 0.93 & $9.06 \mathrm{e}-02$ & $1.44 \mathrm{e}-01$ \\
\hline 75 & suppliers & 1 & 273 & 1.04 & 0.97 & $6.96 \mathrm{e}-02$ & $5.24 \mathrm{e}-01$ \\
\hline 80 & suppliers & 1 & 184 & 1.03 & 1.02 & $7.07 \mathrm{e}-02$ & $7.49 \mathrm{e}-01$ \\
\hline 20 & suppliers & 2 & 996 & 0.79 & 0.47 & $9.74 \mathrm{e}-02$ & $1.56 \mathrm{e}-04 *$ \\
\hline 25 & suppliers & 2 & 928 & 0.83 & 0.53 & $9.48 \mathrm{e}-02$ & $4.71 \mathrm{e}-04 *$ \\
\hline 30 & suppliers & 2 & 889 & 0.91 & 0.57 & $9.79 \mathrm{e}-02$ & $3.98 \mathrm{e}-04 *$ \\
\hline 35 & suppliers & 2 & 825 & 0.91 & 0.57 & $8.73 e-02$ & $3.72 \mathrm{e}-03 *$ \\
\hline 40 & suppliers & 2 & 721 & 0.90 & 0.61 & $8.88 \mathrm{e}-02$ & $6.80 \mathrm{e}-03 *$ \\
\hline 45 & suppliers & 2 & 635 & 0.94 & 0.60 & $9.61 \mathrm{e}-02$ & $5.68 \mathrm{e}-03 *$ \\
\hline 50 & suppliers & 2 & 562 & 0.96 & 0.66 & $1.25 \mathrm{e}-01$ & $3.22 \mathrm{e}-04 *$ \\
\hline 55 & suppliers & 2 & 483 & 1.05 & 0.82 & $8.90 e-02$ & $4.35 \mathrm{e}-02 *$ \\
\hline 60 & suppliers & 2 & 420 & 0.94 & 0.75 & $1.10 \mathrm{e}-01$ & $1.29 \mathrm{e}-02 *$ \\
\hline 65 & suppliers & 2 & 378 & 0.98 & 0.76 & $1.14 \mathrm{e}-01$ & $1.50 \mathrm{e}-02 *$ \\
\hline 70 & suppliers & 2 & 320 & 1.07 & 0.78 & $1.00 \mathrm{e}-01$ & $8.15 \mathrm{e}-02$ \\
\hline 75 & suppliers & 2 & 273 & 1.03 & 0.82 & $8.79 \mathrm{e}-02$ & $2.42 \mathrm{e}-01$ \\
\hline 80 & suppliers & 2 & 184 & 1.15 & 0.92 & $9.24 \mathrm{e}-02$ & $4.13 \mathrm{e}-01$ \\
\hline 20 & bidirectional & 1 & 159 & 0.90 & 0.59 & $1.64 \mathrm{e}-01$ & $2.83 \mathrm{e}-02 *$ \\
\hline 25 & bidirectional & 1 & 154 & 0.88 & 0.34 & $2.27 \mathrm{e}-01$ & $6.72 \mathrm{e}-04 *$ \\
\hline 30 & bidirectional & 1 & 142 & 0.86 & 0.43 & $1.62 \mathrm{e}-01$ & $4.81 \mathrm{e}-02 *$ \\
\hline 35 & bidirectional & 1 & 135 & 0.74 & 0.53 & $1.19 \mathrm{e}-01$ & $3.00 \mathrm{e}-01$ \\
\hline 40 & bidirectional & 1 & 135 & 0.74 & 0.43 & $1.56 \mathrm{e}-01$ & $7.62 \mathrm{e}-02$ \\
\hline 45 & bidirectional & 1 & 119 & 0.62 & 0.39 & $1.26 \mathrm{e}-01$ & $3.02 \mathrm{e}-01$ \\
\hline
\end{tabular}


Table 9 (Continued)

\begin{tabular}{llllllll}
\hline Stress level & Edge type & Year & $N$ & Stressed & Control & D & $p$-value \\
\hline 50 & bidirectional & 1 & 102 & 0.77 & 0.38 & $2.06 \mathrm{e}-01$ & $2.63 \mathrm{e}-02 *$ \\
55 & bidirectional & 1 & 92 & 0.70 & 0.25 & $2.17 \mathrm{e}-01$ & $2.56 \mathrm{e}-02 *$ \\
60 & bidirectional & 1 & 86 & 0.70 & 1.30 & $1.05 \mathrm{e}-01$ & $7.37 \mathrm{e}-01$ \\
65 & bidirectional & 1 & 77 & 0.75 & 1.56 & $1.82 \mathrm{e}-01$ & $1.57 \mathrm{e}-01$ \\
70 & bidirectional & 1 & 69 & 0.83 & 1.64 & $1.74 \mathrm{e}-01$ & $2.49 \mathrm{e}-01$ \\
75 & bidirectional & 1 & 57 & 0.91 & 1.82 & $2.28 \mathrm{e}-01$ & $1.03 \mathrm{e}-01$ \\
80 & bidirectional & 1 & 50 & 0.82 & 2.26 & $1.20 \mathrm{e}-01$ & $8.69 \mathrm{e}-01$ \\
20 & bidirectional & 2 & 159 & 0.70 & 0.52 & $1.45 \mathrm{e}-01$ & $7.17 \mathrm{e}-02$ \\
25 & bidirectional & 2 & 154 & 0.64 & 0.38 & $1.30 \mathrm{e}-01$ & $1.49 \mathrm{e}-01$ \\
30 & bidirectional & 2 & 142 & 0.64 & 0.36 & $1.55 \mathrm{e}-01$ & $6.61 \mathrm{e}-02$ \\
35 & bidirectional & 2 & 135 & 0.63 & 0.47 & $1.19 \mathrm{e}-01$ & $3.00 \mathrm{e}-01$ \\
40 & bidirectional & 2 & 135 & 0.69 & 0.31 & $1.85 \mathrm{e}-01$ & $1.93 \mathrm{e}-02 *$ \\
45 & bidirectional & 2 & 119 & 0.70 & 0.34 & $1.76 \mathrm{e}-01$ & $4.90 \mathrm{e}-02 *$ \\
50 & bidirectional & 2 & 102 & 0.83 & 0.33 & $2.16 \mathrm{e}-01$ & $1.72 \mathrm{e}-02 *$ \\
55 & bidirectional & 2 & 92 & 0.75 & 0.39 & $1.41 \mathrm{e}-01$ & $3.19 \mathrm{e}-01$ \\
60 & bidirectional & 2 & 86 & 0.80 & 0.57 & $1.28 \mathrm{e}-01$ & $4.85 \mathrm{e}-01$ \\
65 & bidirectional & 2 & 77 & 0.88 & 0.96 & $1.04 \mathrm{e}-01$ & $8.04 \mathrm{e}-01$ \\
70 & bidirectional & 2 & 69 & 0.87 & 1.01 & $5.80 \mathrm{e}-02$ & $1.00 \mathrm{e}+00$ \\
75 & bidirectional & 2 & 57 & 0.86 & 1.07 & $1.58 \mathrm{e}-01$ & $4.80 \mathrm{e}-01$ \\
80 & bidirectional & 2 & 50 & 0.82 & 1.22 & $6.00 \mathrm{e}-02$ & $1.00 \mathrm{e}+00$ \\
\hline
\end{tabular}

the industry category of the shocked company. Although we control for several potential confounders, richer datasets may allow to correct for additional variables other than the ones considered in this study.

Although our results show that sudden sales losses, shocks, heavily impact their immediate environment, some companies seem to be resilient against stress. Future investigation would be needed to identify potential protective factors that contribute to stress resilience.

Funding

The authors were supported in part by Hitachi, NSF, NIH, Defense Advanced Research Projects Agency, Boeing, Stanford Data Science Initiative.

\section{Availability of data and materials}

All presented data were used under license for the current study and not available publicly for secondary analysis. Data are potentially available from the authors upon reasonable request and with permission of the National Bank of Slovenia.

\section{Declarations}

Competing interests

The authors declare that they have no competing interests.

\section{Authors' contributions}

RP implemented and designed the analysis and wrote the original draft. JL and PD contributed to the design of the study, review and editing, and provided the data and funding. All authors read and approved the final manuscript.

\section{Author details}

${ }^{1}$ Department of Computer Science, Stanford University, 353 Jane Stanford Way, Stanford, CA 94305, USA. ${ }^{2}$ Bank of Slovenia, Slovenska cesta 35, Ljubljana, 1000, Slovenia.

\section{Publisher's Note}

Springer Nature remains neutral with regard to jurisdictional claims in published maps and institutional affiliations.

Received: 27 May 2020 Accepted: 15 November 2021 Published online: 09 December 2021

\section{References}

1. Carvalho VM, Nirei M, Saito YU, Tahbaz-Salehi A (2021) Supply chain disruptions: evidence from the great East Japan earthquake. Q J Econ 136(2):1255-1321

2. Barrot J-N, Sauvagnat J (2016) Input specificity and the propagation of idiosyncratic shocks in production networks. Q J Econ 131(3):1543-1592 
3. Van Lelyveld I, Liedorp FR (2004) Interbank contagion in the Dutch banking sector

4. Amundsen E, Arnt H (2005) Contagion risk in the Danish interbank market. Technical report, Danmarks Nationalbank Working Papers

5. Cont R, Moussa A, Bastos e Santos E (2010) Network structure and systemic risk in banking systems. In: Network structure and systemic risk in banking systems (December 1, 2010)

6. Bech ML, Atalay E (2010) The topology of the federal funds market. Phys A, Stat Mech Appl 389(22):5223-5246

7. Gai P, Kapadia S (2010) Contagion in financial networks. Proc R Soc A, Math Phys Eng Sci 466(2120):2401-2423

8. De Masi G, Fujiwara Y, Gallegati M, Greenwald B, Stiglitz JE (2011) An analysis of the Japanese credit network. Evol Inst Econ Rev 7(2):209-232

9. Puhr C, Seliger R, Sigmund M (2012) Contagiousness and vulnerability in the Austrian interbank market Oesterreichische Nationalbank Financial Stability Report 24

10. Craig BR, Koetter M, Krüger U (2014) Interbank lending and distress: observables, unobservables, and network structure

11. Martinez-Jaramillo S, Alexandrova-Kabadjova B, Bravo-Benitez B, Solórzano-Margain JP (2014) An empirical study of the Mexican banking system's network and its implications for systemic risk. J Econ Dyn Control 40:242-265

12. Roukny T, Battiston S (2014) A network analysis of the evolution of the German interbank market

13. Cabrales A, Gale D, Gottardi P (2015) Financial contagion in networks

14. Acemoglu D, Ozdaglar A, Tahbaz-Salehi A (2015) Systemic risk and stability in financial networks. Am Econ Rev 105(2):564-608

15. van Lelyveld I et al (2014) Finding the core: network structure in interbank markets. J Bank Finance 49:27-40

16. Glasserman P, Young HP (2016) Contagion in financial networks. J Econ Lit 54(3):779-831

17. Acemoglu D, Ozdaglar A, Tahbaz-Salehi A (2015) Networks, shocks, and systemic risk. Technical report, National Bureau of Economic Research

18. Acemoglu D, Akcigit U, Kerr W (2016) Networks and the macroeconomy: an empirical exploration. NBER Macroecon Annu 30(1):273-335

19. Fujiwara Y, Aoyama H (2010) Large-scale structure of a nation-wide production network. Eur Phys J B 77(4):565-580

20. Letizia E, Lillo F (2019) Corporate payments networks and credit risk rating. EPJ Data Sci 8(1):21

21. Korniyenko MY, Pinat M, Dew B (2017) Assessing the fragility of global trade: the impact of localized supply shocks using network analysis, vol 1. International Monetary Fund

22. Carvalho VM, Tahbaz-Salehi A (2019) Production networks: a primer. Annu Rev Econ 11:635-663

23. Demir B, Javorcik B, Michalski TK, Ors E et al (2018) Financial constraints and propagation of shocks in production networks. Work. Pap., Univ. Oxford, UK

24. Di Giovanni J, Levchenko AA, Mejean I (2014) Firms, destinations, and aggregate fluctuations. Econometrica 82(4):1303-1340

\section{Submit your manuscript to a SpringerOpen ${ }^{\circ}$ journal and benefit from:}

- Convenient online submission

- Rigorous peer review

- Open access: articles freely available online

- High visibility within the field

- Retaining the copyright to your article

Submit your next manuscript at $\boldsymbol{s p r i n g e r o p e n . c o m ~}$ 